\title{
Seasonality and competition select for variable germination behavior in perennials
}

Hanna ten Brink ${ }^{* 1,2}$, Thomas R. Haaland ${ }^{* 2} \& \emptyset_{\text {ystein H. Opedal }}{ }^{3}$

1: Swiss Institute of Aquatic Research, EAWAG, Switzerland. hannatenbrink@gmail.com

2: Department of Evolutionary Biology and Environmental Studies, University of Zurich, Switzerland. trhaaland@gmail.com

3: Department of Biology, Biodiversity Unit, Lund University, Sweden.

oystein.opedal@biol.lu.se

* Co-first authorship and corresponding authors.

Keywords: dormancy, competition, bet-hedging, phenology, seed size, environmental variation

Short title: Germination behavior in seasonal environments

\begin{abstract}
The common occurrence of within-population variation in germination behavior and associated traits such as seed size has long fascinated evolutionary ecologists. In annuals, unpredictable environments are known to select for bet-hedging strategies causing variation in dormancy duration and germination strategies. Variation in germination timing and associated traits is also commonly observed in perennials, and often tracks gradients of environmental predictability. Although bet-hedging is thought to occur less frequently in long-lived organisms, these observations suggest a role of bet-hedging strategies in perennials occupying unpredictable environments. We use complementary numerical and evolutionary simulation models of within- and among-individual variation in germination behavior in seasonal environments to show how bet-hedging interacts with density dependence, life-history traits, and priority effects due to competitive differences among germination strategies. We reveal substantial scope for bet-hedging to produce variation in germination behavior in long-lived plants, when "false starts" to the growing season results in either competitive advantages or increased mortality risk for alternative germination strategies. Additionally, we find that two distinct germination strategies can evolve and coexist through negative frequency-dependent selection. These models extend insights from bet-hedging theory to perennials and explore how competitive communities may be affected by ongoing changes in climate and seasonality patterns.
\end{abstract}

\section{Introduction}

Accurate timing of seasonal phenology is key to population persistence in unpredictable environments. The timing of emergence can have strong and direct effects on individual fitness, and is expected to be subject to strong selection driving local adaptation (Donohue et al. 2010). Indeed, emergence behavior (e.g. patterns of germination or hatching) is often found to vary in predictable ways along environmental gradients (Meyer et al. 1995; Venable 2007; Wagmann et al. 2012; Simons 2014; Pinceel et al. 2017; Rubio de Casas et al. 2017; 
bioRxiv preprint doi: https://doi.org/10.1101/2022.01.13.476161; this version posted January 14, 2022. The copyright holder for this preprint (which was not certified by peer review) is the author/funder, who has granted bioRxiv a license to display the preprint in perpetuity. It is made available under aCC-BY-NC 4.0 International license.

Torres-Martínez et al. 2017; Scholl et al. 2020). In most plants and many animals, the timing of emergence is controlled by dormancy (Vleeshouwers et al. 1995; Finch-Savage and Leubner-Metzger 2006; Baskin and Baskin 2014), and the evolution of emergence behavior is thus tightly linked to the evolution of dormancy mechanisms (Varpe 2017).

Theoretical models of seed dormancy and germination behavior have a long history (Cohen 1966; Venable and Lawlor 1980; Ellner 1985; Geritz et al. 2018; Hughes 2018; Kortessis and Chesson 2019). Most of these, however, have focused on specific systems such as annual plants in desert environments. This system provides a natural starting point because one striking observation demands an explanation: a fraction of the seeds produced each year fail to germinate the next year, and instead lie dormant for another year before germinating at the beginning of the second growing season following their dispersal (Gremer and Venable 2014). While this reduction in number of seedlings may seem a waste of resources most years, such a strategy has been identified as a risk-spreading adaptation to avoid complete recruitment failure in the event of a bad year. Prolonged seed dormancy and variation in germination timing have come to represent the archetype of a bet-hedging strategy, i.e. a genotype-level strategy that sacrifices some short-term (arithmetic-mean) fitness gains in order to lower its fitness variance over time (Levins 1962; Cohen 1966; Venable 2007). Such bet-hedging strategies have received considerable empirical and theoretical attention as a major mode of adaptation to unpredictable environments (Seger and Brockmann 1987; Simons 2011; Starrfelt and Kokko 2012).

Empirical and theoretical studies of bet-hedging have yielded a good understanding of how different types of risk-spreading adaptations co-evolve, interact, and cancel each other out. For example, if phenotypic polymorphisms or continuous variation ensures that fitness correlations among related individuals are sufficiently low, then there is less need for other costly bet-hedging strategies at the individual level such as 'safer' offspring phenotypes that are weaker competitors but better able to cope with environmental variation (Venable and Brown 1988; Starrfelt and Kokko 2012; Haaland et al. 2020; Escobar et al. 2021). The scope for bet-hedging is also lowered if the spatiotemporal scale of environmental variation (what is often called environmental 'grain' in bet-hedging terms) already ensures that individuals in a population experience different conditions and thus uncorrelated fitness returns. In a spatially fine-grained environment the population is exposed to a wide range of different conditions at any given time (as opposed to coarse-grained environments where all individuals experience the same conditions), and in such cases, genotype-level diversification or other bet-hedging strategies are not selectively favored (Levins 1962; Starrfelt and Kokko 2012). Furthermore, longer lifespans with a larger number of selective events over which fitness can accumulate (e.g. an individual experiencing multiple consecutive breeding seasons with variable conditions) also reduces the need for any variance reduction if fitness payoffs among selective events are uncorrelated (Haaland et al. 2019).

Given these insights, it is unsurprising that most models of bet-hedging, as well as many of the best-documented empirical examples, consider rather specific types of short-lived organisms with discrete generations occupying highly variable, coarse-grained environments, such as germination strategies of desert annuals, or overwintering strategies for organisms living in ephemeral ponds (Furness et al. 2015; García-Roger et al. 2016; Wang and Rogers 2018). However, this focus has also led to a knowledge gap regarding the evolution of seemingly 'risk-spreading' traits in longer-lived organisms, as these may require other 
bioRxiv preprint doi: https://doi.org/10.1101/2022.01.13.476161; this version posted January 14, 2022. The copyright holder for this preprint (which was not certified by peer review) is the author/funder, who has granted bioRxiv a license to display the preprint in perpetuity. It is made available under aCC-BY-NC 4.0 International license.

explanations than bet-hedging in its strictest sense. Variation in seed germination behavior is seen not only in annuals, and is at least sometimes associated with variation in seed size (Rees 1996; Simons and Johnston 2000; Susko and Lovett-Doust 2000; Norden et al. 2009; Harel et al. 2011; Martins et al. 2019). A classic example of within-individual variation in seed size is seed heteromorphism, as observed e.g. in many Asteraceae and Chenopodiaceae (reviewed in Venable 1985; Imbert 2002), where distinct seed morphs differ in their dispersal abilities and germination behavior (Venable et al. 1987; Brändel 2004; Fumanal et al. 2007; Yao et al. 2010; Wang et al. 2012). Continuous variation in seed size is also common in natural populations, and may relate to variation in germination behavior (Pélabon et al. 2021). Within species, larger seeds are generally more likely to germinate and/or germinate earlier than do smaller ones (Biere 1991; Simons and Johnston 2000; Tremayne and Richards 2000; Galloway 2001; Pélabon et al. 2005), but the opposite pattern of seed mass increasing the time necessary to break dormancy and induce germination is also observed (Martins et al. 2019).

Seed size variation is thus a common mechanism for producing seeds with variable duration of dormancy and/or variable germination time both within individuals as well as within an inflorescence (Pélabon et al. 2021). As argued, existing bet-hedging models alone are not able to explain the ubiquity of seed heteromorphism or continuous seed size variation as observed in perennials (Martins et al. 2019). Although several other non-mutually exclusive hypotheses exist, including but not limited to variance-sensitivity due to asymmetrical fitness costs versus benefits (Bednekoff 1996; Bårdsen et al. 2008), fluctuating selection or fluctuations in priority effects (Chesson 2000; ten Brink et al. 2020), competitive asymmetries among offspring types (Geritz 1995) and negative frequency-dependent selection (Metcalf et al. 2015; Poethke et al. 2016), these have seldom been analyzed jointly (but see Rees et al. 2004). In Scholl et al.'s (2020) recent analysis of the flora of the south-east United States, annuals were not detectably more likely to exhibit seed heteromorphism than were perennials, suggesting that selection for within-individual variation in germination behavior may be common also in long-lived plants where bet-hedging is less strongly favored.

Here, we explore the evolution of individual variation in dormancy of long-lived plants in seasonally varying environments, using both numerical and simulation models covering a range of ecological scenarios. Our numerical model derives general predictions for when bethedging can favor within-plant variation in germination behavior as an adaptation to seasonal environmental variation in perennials. To this end we compare long-term arithmetic and geometric growth rates of populations exhibiting different germination strategies. This model uses a simple setup assuming two discrete seed morphs, a "small" seed with a short dormancy period, and a "large" seed with a long dormancy period. This analysis identifies the strength of priority effects and factors affecting the riskiness of early germination (probability of a "false start" and small-seed juvenile survival) as key determinants of optimal seed strategies and reveals ample scope for bet-hedging in within-plant seed variation. We complement this numerical model with individual-based evolutionary simulations of both mean and standard deviation of dormancy duration modelled as continuous traits. This model accounts for density- and frequency dependence and allows us tease apart the relative effects of bethedging, competition, and fluctuating selection by adjusting parameters such as lifespan, the grain of the environment, and the strength of priority effects. We let rainfall patterns vary predictably and unpredictably within and among years, emulating the wet- and dry-season dynamics seen in large parts of the tropics where intermittent dry-season rains can trigger germination of certain seed types. However, we note that this model setup applies equally 
well to other stochastic seasonal changes between harsh and favorable conditions, such as the onset of warmer spring weather in temperate regions where "false starts" of warm temperatures may still be followed by harmful frosts.

\section{Selection for within-plant variation in germination behavior}

\section{Model setup}

We first present a numerical model where we assume that plants can produce two seed morphs, here "small" and "large" seeds, that differ in the amount of rainfall required for germinating. Each year consists of a dry and a wet season, and with probability $p_{\mathrm{f}}$ there is some intermittent rainfall (a "false start") during the dry season, which triggers germination of small seeds. These early seedlings emerging during intermittent rains have a high probability of dying due to drought, and therefore only a small chance to recruit into the adult population during such years. Large seeds, on the other hand, require more rainfall in order to germinate, and therefore remain dormant through any intermittent rains. When the wet season begins, small seeds have a competitive advantage over large seeds (given that there was no intermittent rain during the dry season) because they germinate faster, giving the seedlings a head start to growth, and thus a higher probability of recruitment into the adult population.

We designate as $f$ the fraction of small seeds produced by a plant, so that a fraction $1-f$ are large seeds. Assuming no density- or frequency-dependence, the equations for population growth in the two different types of years (with or without false rains) become

$$
N(t+1)_{\text {false }}=N(t) s_{\mathrm{a}}+N(t) y\left[(1-f)+f s_{\text {juv }}\right]
$$

$$
N(t+1)_{\text {normal }}=N(t) s_{\mathrm{a}}+N(t) y[(1-f) c+f]
$$

where $N$ is the number of adult plants, $s_{\mathrm{a}}$ is annual adult survival, $y$ is seed yield per plant, $f$ is the fraction of small seeds produced, $s_{\text {juv }}$ is the juvenile survival of small seeds in the case of intermittent rain, and $c$ is the relative competitive disadvantage of large seeds compared to small seeds in normal years. If $c$ is low, small seeds benefit from a strong priority effect in terms of competition for recruitment, whereas if $c$ is large (near 1), small and large (respectively early- and late-germinating) seeds are competitively similar in years without intermittent rain (weak priority effects).

To find the optimal strategy $f^{*}$ we calculate long-term geometric growth rate $\lambda_{\text {geom }}$ for a given probability $p_{\text {f }}$ of years having a false start during the dry season (eq. 2). In order to identify any bet-hedging effect, we compare this strategy with the one that optimizes arithmetic mean fitness (eq. 3).

$$
\begin{aligned}
& \lambda_{\text {geom }}=p_{\mathrm{f}} * \log \left\{N(t+1)_{\text {false }}\right\}+\left(1-p_{\mathrm{f}}\right) * \log \left\{N(t+1)_{\text {normal }}\right\} \\
& \lambda_{\text {arit }}=\log \left\{p_{\mathrm{f}} * N(t+1)_{\text {false }}+\left(1-p_{\mathrm{f}}\right) * N(t+1)_{\text {normal }}\right\}
\end{aligned}
$$


bioRxiv preprint doi: https://doi.org/10.1101/2022.01.13.476161; this version posted January 14,2022 . The copyright holder for this preprint (which was not certified by peer review) is the author/funder, who has granted bioRxiv a license to display the preprint in perpetuity. It is made available under aCC-BY-NC 4.0 International license.

Maximizing (2) over $f$ identifies the optimal strategy $f^{*}$ leading to the highest population growth rate as a function of environmental conditions (years with or without false starts). This is calculated numerically because we do not obtain a closed-form expression for $f^{*}$.

\section{Results}

This simple model reveals that there is considerable scope for bet-hedging (optimal strategies differ depending on whether arithmetic or geometric mean growth rate is being maximized), and that there are large ranges of parameter values for which the optimal strategy is a mix of small and large seeds (Fig. 1). Arithmetic mean fitness maximization always favors a pure strategy $\left(f^{*}=0\right.$ or 1$)$, and the transition between parameter spaces favoring one or the other is indicated by a red line. In contrast, geometric mean fitness can favor mixed strategies,
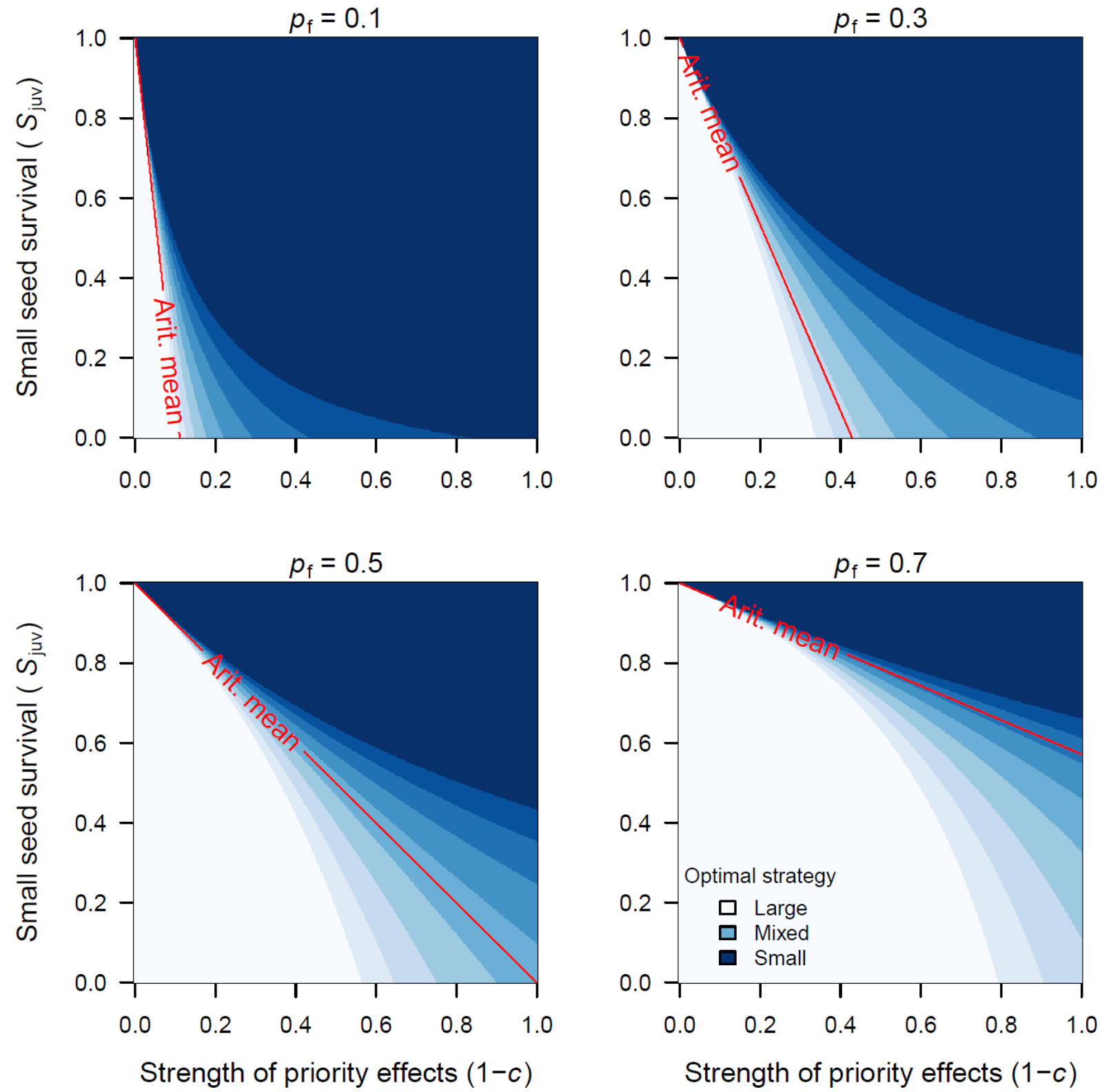

Fig. 1: Optimal fraction of small seeds $\left(f^{*}\right)$ for different values of small-seed survival under false rains, $s_{\text {juv }}(\mathrm{y}-$ axis), strength of priority effects, 1-c (x-axis), and probabilities of false rains, $p_{\mathrm{f}}$. The red line shows where arithmetic mean fitness maximization switches from producing only large seeds ( $f=0$, below the line) to only small seeds $\left(f=1\right.$, above the line). Adult survival $s_{\mathrm{a}}=0.9$, which translates to an average adult lifespan of 10 years. 
bioRxiv preprint doi: https://doi.org/10.1101/2022.01.13.476161; this version posted January 14, 2022. The copyright holder for this preprint (which was not certified by peer review) is the author/funder, who has granted bioRxiv a license to display the preprint in perpetuity. It is made available under aCC-BY-NC 4.0 International license.

especially when the fitness difference between large and small seeds varies extensively across years. This occurs when $s_{\text {juv }}$ is small (low juvenile survival through the dry season following intermittent rain), $c$ is small (small seeds have a strong competitive advantage over large seeds), and $p_{\mathrm{f}}$ is intermediate (years with and without a false start are about equally likely).

\section{Individual-based model of mean and variance in dormancy}

\section{Model setup}

Here, we build an individual-based simulation model of the joint evolution of mean and variance in dormancy duration in perennial plants. We assume that seed germination is determined by the dormancy period $d_{z}$, which functions as an obligate "biological clock" preventing germination until a certain time $d_{\mathrm{z}}$ has passed (see table 1 for an overview of all mathematical notation and baseline parameter values used in the individual-based model). Germination of a seed occurs with probability 1 as soon as its age (in weeks) is greater than $d_{\mathrm{z}}$ and a rainfall occurs that exceeds some threshold amount $R_{\text {thres. }}$. We here allow continuous, normally distributed within-individual variation in $d_{\mathrm{z}}$ (rather than just e.g. "small" and "large" seeds), determined by two haploid genes $d_{\mu}$ and $d_{\sigma}$ that control respectively the mean and standard deviation (in weeks) of the distribution of $d_{\mathrm{z}}$ among an individual's offspring. The actual phenotypic trait value of an offspring $i$ is thus randomly drawn from a Gaussian distribution determined by its parent's genetic values: $d_{z, i} \sim \mathrm{N}\left(d_{\mu}, d_{\sigma}^{2}\right)$. Because week number is an integer, we handle non-integer values by probabilistically assigning germination week (i.e., given that a rainfall $R>R_{\text {thres }}$ has occurred, a seed with $d_{\mathrm{z}, i}=23.6$ has a $40 \%$ chance of germinating in week 23 , and $60 \%$ chance of germinating in week 24).

Population initialization. Each replicate simulation starts with $N_{0}$ adult individuals. Each of these individuals are independently assigned a random combination of gene values, where starting $d_{\mu}$ values are normally distributed with a mean of 15 and standard deviation of 3 weeks, and the $d_{\sigma}$ values with a mean of 3 and a standard deviation of 3 weeks. Negative $d_{\sigma}$ values are set to 0 . We start the simulations with ample standing genetic variation for computational purposes (but see Supplementary Material Part 2 for control simulations initialized without genetic variation).

Abiotic conditions. We model time steps of one week and assign the first 26 weeks of a year as the dry season and the last 26 weeks as the wet season. Dry-season rainfall varies stochastically within years, with 26 weekly rainfalls randomly drawn at the start of the year

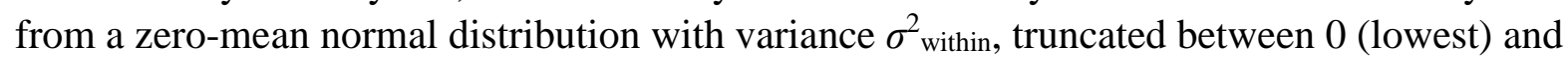
1 (highest). The actual mean and variance of these weekly rainfalls thus differ from 0 and

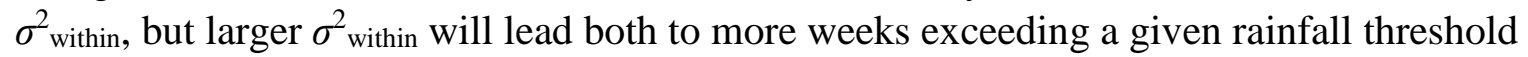
$R_{\text {thres }}$ required for seed germination and to an increase in the survival probabilities of germinated seeds (Fig. 2). Weekly rainfall in the wet season is always equal to 1 .

We examine evolutionary outcomes under coarse-grained and fine-grained environmental variation. Under coarse-grained environmental variation, we assume that all seeds experience the same sequence of weekly rainfalls $\boldsymbol{R}$ (a vector of 52 values) but $\boldsymbol{R}$ differs among years. Under fine-grained environmental variation, different $\boldsymbol{R}$ vectors are assigned to individual seeds at random. Specifically, we produce 20000 sequences of weekly rainfall and assign each 
seed a random $\boldsymbol{R}$ chosen among these. Thus, experienced rainfall will vary a lot among individuals within a year in this scenario, but average rainfall will vary less across years.

Survival of seedlings and adults. After setting the weekly rainfall of a particular year, we determine the survival probability of seedlings and adults in that year. We assume that survival increases both with rainfall and with the age of the plant. The probability of survival for an individual $i$ with age $a_{i, t}$ in a given week $t$ with rainfall $R_{t}$ (or $R_{i, t}$ in the fine-grained scenario) equals

$$
S_{i, t}\left(a_{i, t}, R_{t}\right)=\frac{S_{\min } R_{t}}{\mu_{\mathrm{wet}}}+\frac{\left(S_{\max }-S_{\min } R_{t}\right)}{1+\exp \left(-\delta_{1}\left(a_{i, t}-a_{\mathrm{infl}}\left(1-R_{t} \delta_{2}\right)\right)\right)},
$$

i.e. a sigmoid function of seedling age, the lower asymptote of which increases with increasing rainfall (Fig. 2A, B). Note that rainfall also affects the horizontal position of the function (how far "along" the x-axis the seed has come in terms of survival), and that the strength of this effect increases with the parameter $\delta_{2}$.

With the rainfall data of a particular year and the survival function (eq. 4), we can now calculate each seedling's survival probability (Fig. 2C), which is given by the product of its (age- and rain-dependent) survival probabilities of each week from germination time $t_{\text {germ }}$ until the end of the year:

$$
S_{i}\left(t_{\mathrm{germ}}, \boldsymbol{R}\right)=\prod_{t=t_{\text {germ }}}^{52} S_{i, t}\left(a_{i, t}, R_{t}\right)
$$

To determine whether a seedling survives its first year, we draw a random number from a uniform distribution $[0,1]$. If this random number is lower than the survival probability of the seedling, the seedling will survive. Otherwise it is removed from the population. Likewise, we can calculate which of the adults will be allowed to reproduce (see below) and survive to the
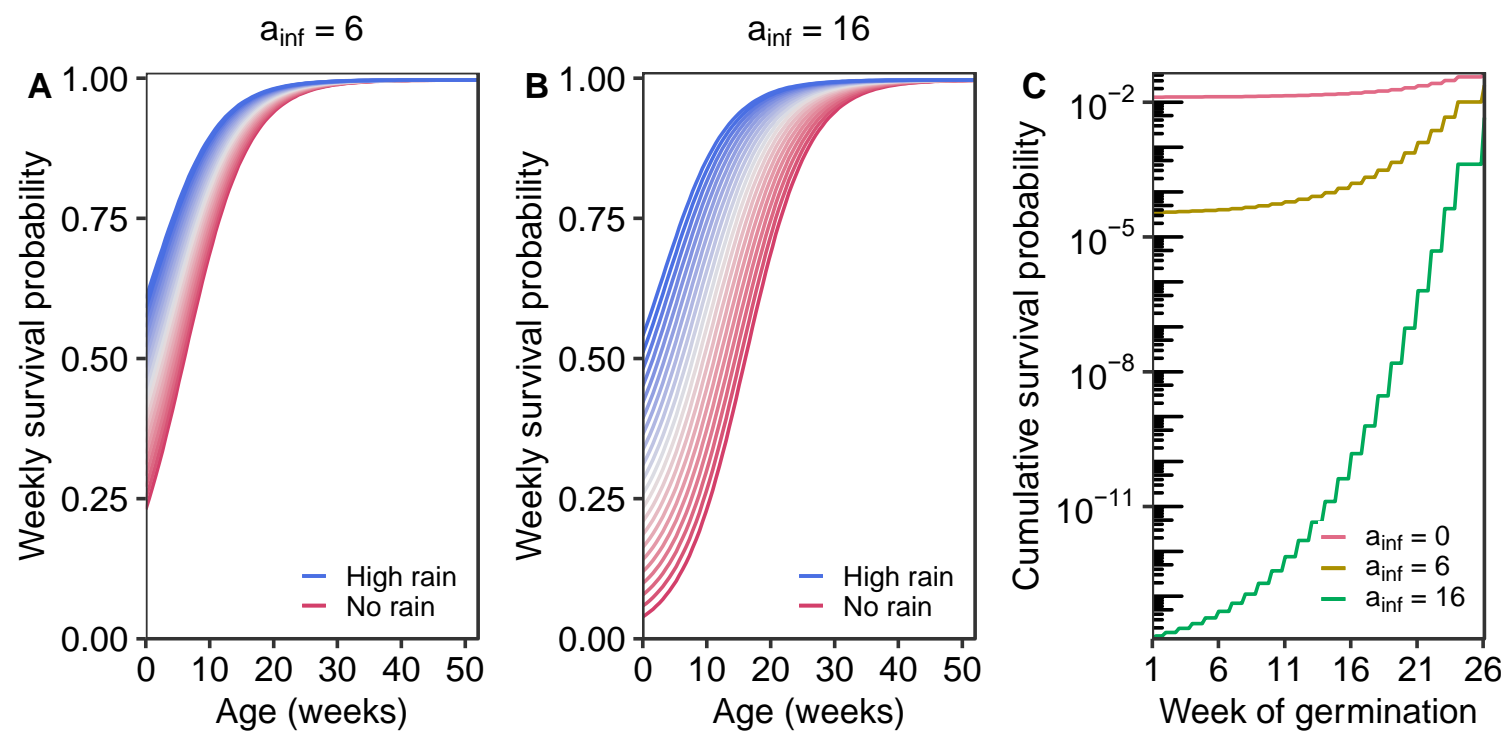

Fig. 2: Seedling survival functions. A and B: Weekly survival probability for different amounts of rainfall (blue lines: $\boldsymbol{R}=1$; red lines: $\boldsymbol{R}=0$ ) and varying the inflection point $a_{\mathrm{inf}}$ of the juvenile survival function $S i, t$ (panels). C: Effect of week of germination (x-axis) and $a_{\text {inf }}$ (colored lines) on the probability of a seedling surviving its first year (52 weeks since germination), assuming a worst-case scenario with no rainfall in the dry season and constant high rainfall $(\boldsymbol{R}=1)$ in the wet season. 
next year. We assume that survival for plants of age $a_{i} \geq 52$ weeks, $S_{\text {adult }}$, is independent of age and rainfall.

Recruitment and density dependence. We assume that only $K$ adult plants can live in the environment. At the end of the wet season, we determine which of the seedlings that germinated in this year will recruit into the adult population. We first calculate the number of available slots ( $K$ minus the number of surviving adults), and then fill the empty slots with seedlings. Recruitment success can be either age-dependent, with slots filled sequentially by older seedlings first ('priority effects'), or age-independent, with slots filled at random.

Table 1: Overview of variables and parameters of the individual-based model.

\begin{tabular}{|c|c|c|}
\hline $\begin{array}{l}\text { Parameter } \\
\text { in text }\end{array}$ & Description & $\begin{array}{l}\text { Default values and } \\
\text { range }\end{array}$ \\
\hline \multicolumn{3}{|c|}{ A) Abiotic environment parameters } \\
\hline$\sigma^{2}$ within & Variance in mean weekly rainfall within a year. & We explore $[0,4]$. \\
\hline$R_{t}$ & Realized rainfall in a particular week. & {$[0,1]$} \\
\hline \multicolumn{3}{|c|}{ B) Survival function parameters } \\
\hline$a$ & Age of seedling. & \\
\hline$S_{\min }$ & $\begin{array}{l}\text { Lower asymptote of the seedling survival function } \\
\text { (survival probability given } a=1 \text { and } R_{\mathrm{t}}=0 \text { ). }\end{array}$ & Default 0.3 \\
\hline$S_{\max }$ & $\begin{array}{l}\text { Upper asymptote of the seedling survival function } \\
\text { (survival probability when } a \text { and } R_{\mathrm{t}} \text { are large). }\end{array}$ & Default 0.997. \\
\hline$\delta_{1}$ & Affects the steepness of the survival function. & Default 0.2 \\
\hline$\delta_{2}$ & Enhances the effect of rain on the survival function. & Default 0.8 \\
\hline$a_{\text {infl }}$ & $\begin{array}{l}\text { Age (weeks) at which the survival function increases } \\
\text { most steeply. }\end{array}$ & $\begin{array}{l}\text { Default } 6 \text {. We also } \\
\text { examine } a_{\text {infl }}=\{0,16\}\end{array}$ \\
\hline \multicolumn{3}{|c|}{ C) Genes and trait values } \\
\hline$d_{\mu}$ & $\begin{array}{l}\text { Genetic value determining expected (mean) seed } \\
\text { dormancy. }\end{array}$ & - \\
\hline$d_{\sigma}$ & $\begin{array}{l}\text { Genetic value determining standard deviation of seed } \\
\text { dormancy. }\end{array}$ & - \\
\hline$d_{, z, i}$ & Actual individual dormancy period of seed $i$ (in weeks). & \\
\hline \multicolumn{3}{|c|}{ D) Demographic and evolutionary parameters } \\
\hline$K$ & Carrying capacity. & Default 5000. \\
\hline 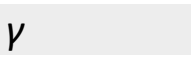 & Yearly fecundity per adult plant. & Default 50. \\
\hline$m$ & Per-locus mutation rate. & Default 0.01 \\
\hline$m_{\text {size }}$ & $\begin{array}{l}\text { Size of mutational effects (The standard deviation of } \\
\text { the Gaussian distribution from which the new trait } \\
\text { value is chosen). }\end{array}$ & Default 0.01 \\
\hline$N_{0}$ & Starting population size. & Default equal to $K$. \\
\hline$c$ & $\begin{array}{l}\text { Strength of priority effects (competitive advantage to } \\
\text { germinating earlier). Proportion of recruitment that } \\
\text { does not depend on seedling age. }\end{array}$ & $\begin{array}{l}\text { Default } 1 . \text { We also } \\
\text { examine } c=0\end{array}$ \\
\hline$S_{\text {adult }}$ & $\begin{array}{l}\text { Weekly adult survival probability. Yearly survival } \\
\text { probability becomes } s_{\text {adult }}{ }^{52} \text {. Expected lifespan (in } \\
\text { weeks) becomes } 1 /\left(1-s_{\text {adult }}\right)\end{array}$ & $\begin{array}{l}\text { Default } 0.997 . \text { We also } \\
\text { examine } 0.994 \text {. }\end{array}$ \\
\hline
\end{tabular}


Reproduction, inheritance and mutation. At the end of the wet season, all adult plants (i.e. individuals older than 52 weeks, not the juveniles that were just recruited) reproduce asexually. Individual seed production is Poisson distributed with a mean fecundity of $\gamma$. Offspring inherit their parent's gene values for determining dormancy duration $\left(d_{\mu}, d_{\sigma}\right)$, but not their actual phenotype $d_{z}$. Each locus has an independent probability $m$ of experiencing mutation. Mutational effects on $d_{\mu}$ are of constant effect, such that the new gene value is drawn from a normal distribution with a mean equal to the previous value, and a standard deviation of $m_{\text {size. }}$ For $d_{\sigma}$, whose value is bounded by 0 , mutations that would lead to negative values are mirrored around 0 , ensuring that the new gene value is positive.

Data generation and analysis. Simulations run for 100.000 years. We present results derived from averages over the last 1000 years (but see Fig. S2), in order to eliminate any irregularities produced by yearly environmental variation. Each scenario is replicated over 10 independent runs for course-grained environmental variation. In case of fine-grained environmental variation we replicate each scenario 3 times only because variation among replicates is negligible.

We find, under some conditions, that two strategies can coexist in the population until the end of the simulations. To aid data interpretation, we plot the trait values $d_{\mu}$ and $d_{\sigma}$ and the corresponding dormancy periods $d_{z}$ for each simulation and determine visually whether there are one or two clusters in trait space. If there are two clusters we use the k-means method (Hartigan \& Wong, 1979) to allocate individuals to a certain cluster. This method partitions the strategies into groups so that the sum of squares from points to the assigned cluster centers is minimized. The algorithm uses random data points as starting locations to sort individuals to their nearest cluster center, so we let it run 20 times per replicate in order to minimize this randomness introduced when determining starting cluster centers. We implemented the model in $\mathrm{C}++$; the code will be made available online. Simulations were run using GNU parallel (Tange 2021).

\section{Results}

Despite the added ecological and evolutionary complexity of the individual-based simulation model, we overall find that these results correspond well with those of the simpler phenomenological model (section 1). Specifically, we will present four findings that clearly demonstrate the relative effects of competition, life-history, and environmental variation in determining within- and among-individual variation in germination behaviour and associated traits. (i) In the absence of any priority effects, germination always occurs at the beginning of the wet season, because the risks of early germination are never worth taking. (ii) Adding priority effects via age-dependent competition for recruitment favors greater risk-taking, in the form of earlier germination and/or spreading of germination. We often find coexistence of multiple strategies because some years (with more favorable dry-season rainfall patterns) favor more competitive (and risky) strategies than others, i.e. potential for both within- and among-plant seed size variation. (iii) Only intermediate seedling mortality selects for mixed strategies. Any within- or among-individual dormancy variation disappears if dry-season conditions are either very benign or very harsh. (iv) Under density-dependence, long adult lifespan increases competition because fewer 'slots' are available for seedlings to colonize and eventually recruit into the adult population, leading to increased risks taken via early 
germination and/or spreading of germination. Finally, alongside findings (i-iv), we investigate bet-hedging effects of genotype-level fitness variance caused by among-individual fitness correlations by comparing results obtained in temporally coarse-grained environments (all individuals experience the same rainfall patterns in a given year, resulting in high among-year variation) with those obtained in fine-grained environments (rainfall patterns are assigned independently for all individuals in a given year, resulting in low among-year variation). In fine-grained environments, we never detect any spreading of germination, indicating that our scenarios favoring within-individual seed size variation can be attributed to the interaction between age-dependent competition for recruitment and bet-hedging. This result also importantly highlights that bet-hedging in germination strategies is not driven per se by weekly rainfall variation within years, $\sigma^{2}$ within, but also by the spatial scale of rainfall variation, which affects correlations in environmental conditions experienced among individuals within populations.

(i) No priority effects lead to fixed, safe strategies. Without priority effects, i.e. all competition for recruitment is independent of seedling age, obligate dormancy evolves causing germination at the beginning of the wet season (Fig. S1, evolved values of $d_{\mu}$ form a flat line over a range of within-year rainfall variance $\sigma^{2}$ within). This holds even under high $\sigma^{2}$ within, for which dry-season germination and seedling survival may often be possible, because there are no competitive benefits to early germination and so even small risks are not worth taking. Accordingly, within-individual variation in dormancy period $d_{\sigma}$ evolves values close to 0 . Bet-hedging has no effect on the evolution of $d_{\mu}$ or $d_{\sigma}$ in this scenario, because there is no variance in expected fitness nor fitness correlations among related individuals (Fig. $\mathrm{S} 1$, dots show coarse-grained and stars fine-grained environments). Such fixed strategies and absence of evolutionary conflicts of interest in the short and long term are also predicted by our density-independent phenomenological model (Fig. 1, large seeds are always favored when $c=1$, i.e. leftmost part of each subplot, regardless of whether arithmetic or geometric mean fitness is maximized).

(ii) Priority effects favor risky strategies and within- and among-individual variation. When adding priority effects in the form of age-dependent recruitment success, we observe both earlier germination $\left(d_{\mu}<26\right)$ and increased variation in dormancy $\left(d_{\sigma}>0\right)$. Interestingly, we often observe stable coexistence between two distinct strategies, one involving earlier but less variable germination (low $d_{\mu}$ and low $d_{\sigma}$ ), and one involving later but more variable germination (higher $d_{\mu}$ and high $d_{\sigma}$ ). Because of this evolved genetic correlation, simple population-wide genotype averages are not informative. Fig. 3 (and supplementary figures S4 and S5) therefore shows resulting multilocus strategies in genotype space ( $d_{\mu}$ and $\left.d_{\sigma}\right)$ from 10 replicate simulations as separate colors, with points connected by a line whenever multiple strategies coexisted until the end of the simulation. Actual distributions of germination timing for each of 5 representative replicates are shown as colored inset histograms on the right. These demonstrate that the more variable strategy (darker hued histograms) produces some seeds that germinate earlier than the less variable strategy (lighter hued histograms), with these early seeds winning the competition for recruitment in years where dry season rainfalls are favorable. In years with unfavorable 'false' dry season rains (followed by several weeks of no rain before the start of the wet season in week 26), the seeds of the more variable strategy germinate later on average. 
Because some simulations ended with one and others with two distinct strategies, we ran additional simulations with these parameter combinations to determine the stability of coexistence between the distinct strategies (low or high $d_{\mu}$ and $d_{\sigma}$ ), when either of the strategies can be lost due to e.g. demographic and environmental stochasticity. In Fig. S2 we show that each strategy is successful in invading a population consisting of individuals using the alternative strategy. This indicates that negative frequency-dependent selection favors each strategy when rare, leading to stable coexistence, and that results in e.g. Fig. 4 and S4 with only a single strategy may represent only transient losses of a strategy, after stochastic events and before sufficient mutations again generate the 'right' multilocus genotype to invade. Note that we started simulations with large variation in $d_{\mu}$ and $d_{\sigma}$. To check whether two coexisting strategies would also evolve if simulations were initiated with less variation, we ran control simulations starting with no genetic variation (Fig. S3). These confirmed that the observed coexistence evolves also in these cases, via an evolutionary branching event.
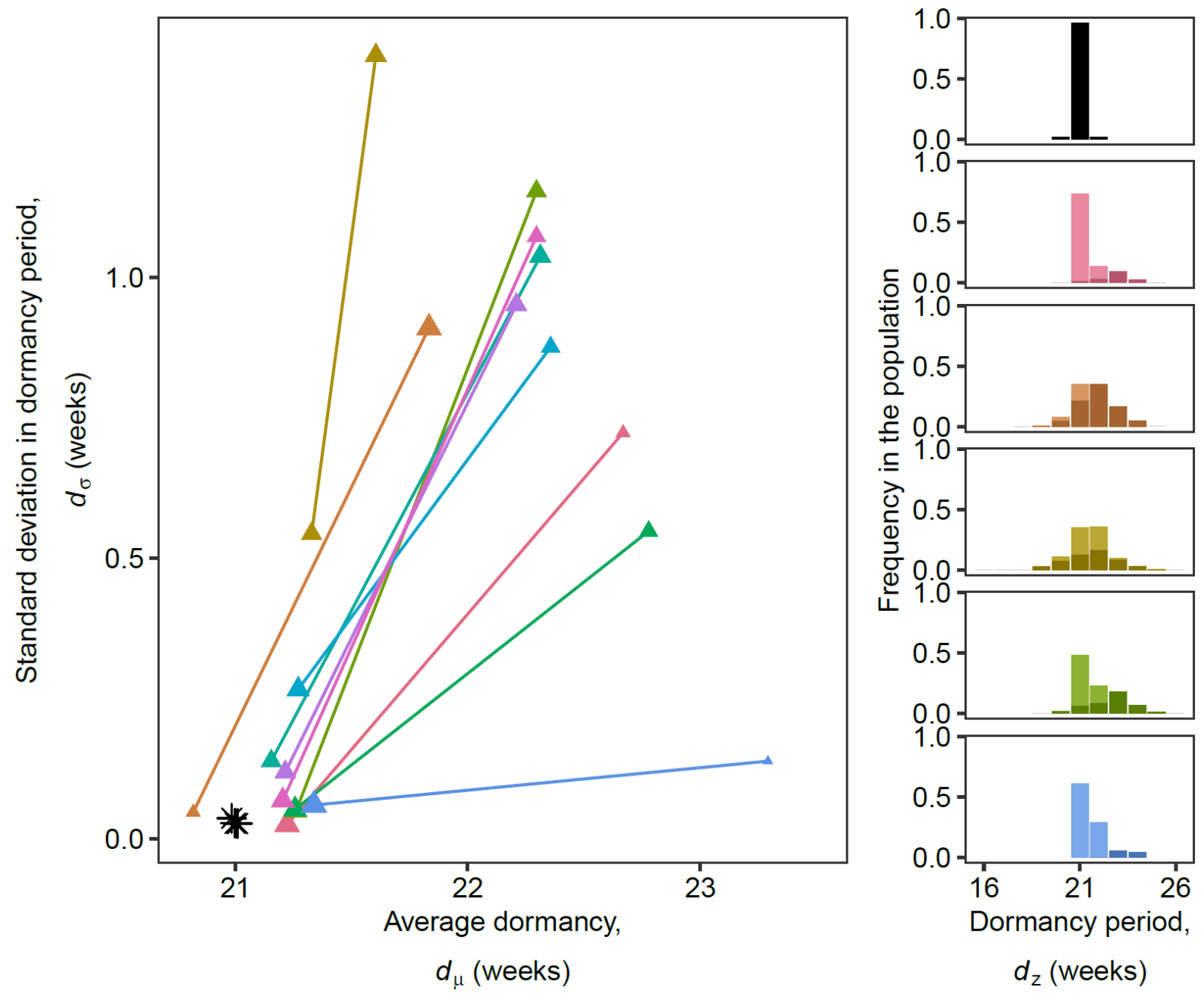

Figure 3: Left panel shows average evolved seed dormancy strategies represented by a combination of dormancy period $\left(\mathrm{d}_{\mu}\right)$ and standard deviation in dormancy period $\left(d_{\sigma}\right)$ when dry season rainfall variance $\sigma^{2}$ within $=2$ (see table 1 for other baseline parameter values). Each population is represented in trait space by two colored triangles connected by a solid line if two strategies coexisted in the population at the end of the simulation, with triangle sizes proportional to the fraction of the population using each strategy. The black stars represent populations in fine-grained environments (that always evolved a single strategy). Histograms on the right shows the distributions of the actual dormancy periods produced by the genotypes in the population. Histogram colors correspond to point color in the left panel. For simulations with two coexisting strategies the distribution of dormancy periods is plotted in a darker hue for the strategy with higher $d_{\sigma}$. 
We also note that under a fine-grained rainfall pattern (black star and histogram in Fig. 3), no variation in dormancy evolves within individuals $\left(d_{\sigma}\right.$ remains low) nor among individuals (two distinct strategies never occur). Although age-dependent competition for recruitment now favors earlier germination than occurred without priority effects $\left(d_{\mu}<26\right)$, this competitive pressure does not result in variable germination timing. Thus, we identify both within- and among-individual variation in seed dormancy as resulting from an interaction between bet-hedging in coarse-grained variable environments, priority effects due to agedependent seedling competition, and negative frequency-dependent selection.

(iii) Only intermediate mortality risks select for mixed strategies. Because seedling mortality strongly affects the risks of early germination, any variation in germination timing occurs at intermediate levels of mortality risk in the dry season. In the scenario illustrated in Fig. 4A we adjust the parameter $a_{\text {infl, }}$, the inflection point of the survival function, i.e. the age at which survival rises steepest, such that higher (later) $a_{\text {infl }}$ entails higher overall mortality (see Fig. 2). We find that low mortality (blue results in Fig. 4A) always selects for germinating as soon as possible (because of priority effects), i.e. $d_{\mu}=0$ and $d_{\sigma}=0$. On the other hand, very high mortality (due to high $a_{\text {infl }}$; black results in Fig. 4A) always selects for germinating right at the start of the wet season $\left(d_{\mu}=26\right.$ and $\left.d_{\sigma}=0\right)$. Thus, only intermediate mortality risks (Fig. 3) favor variable dormancy periods. Again, this general result corresponds well with our phenomenological model (Fig. 1).

(iv) Low adult mortality increases the strength of priority effects. A final observation in this model is that, in contrast to traditional predictions from bet-hedging theory, longer lifespans select for increased spreading of germination. This effect arises because of our implementation of density-dependence, where lower adult mortality means that fewer 'slots' are opened up every year for seedlings to recruit into. This increases the intensity of agedependent competition, which leads to stronger selection for early germination the higher the
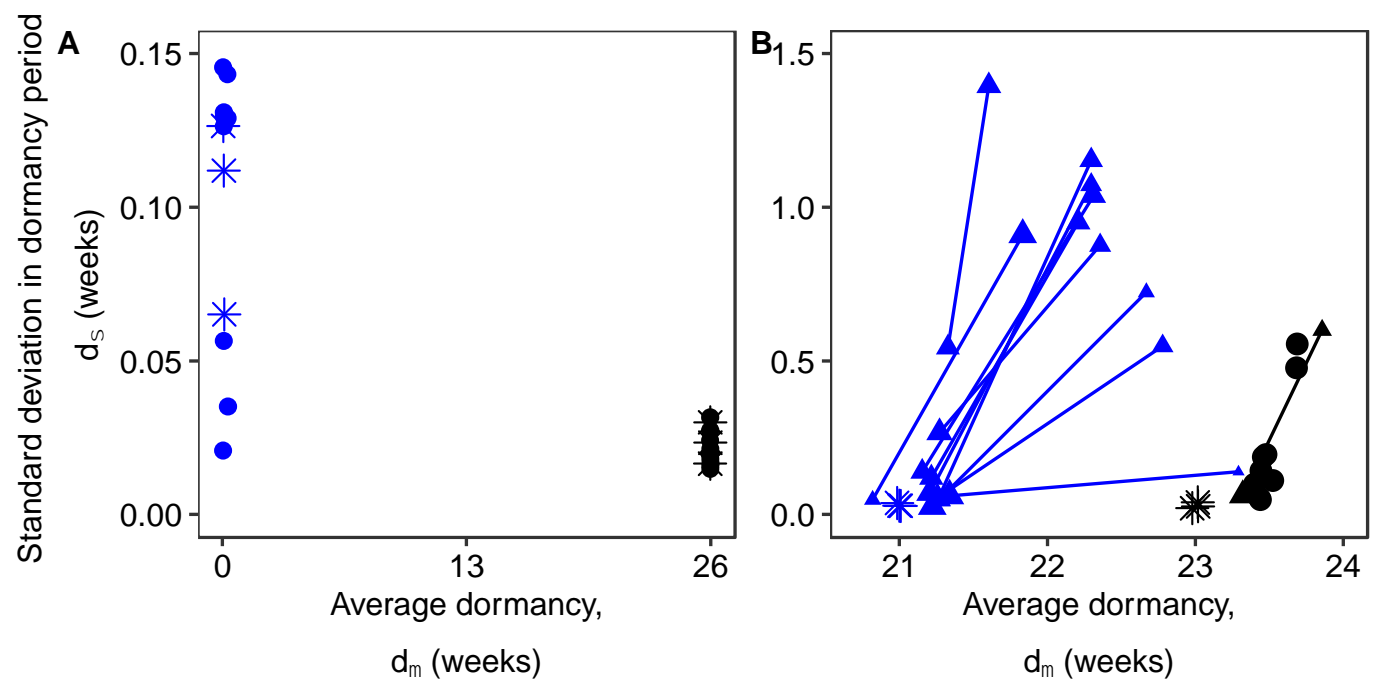

Fig. 4 Average evolved seed dormancy strategies combining dormancy period $\left(\mathrm{d}_{\mu}\right)$ and standard deviation in dormancy period $\left(\mathrm{d}_{\sigma}\right)$ when dry season rainfall variance $\sigma^{2}{ }_{\text {within }}=2$ (See table 1 for other baseline parameter values). Each population is represented in trait space by one point if exhibiting a single strategy at the end of the simulation (circle), or two points if two strategies coexisted in the population at the end of the simulation (triangles connected by a solid line), with point sizes proportional to the fraction of the population using each strategy. Stars represent populations in fine-grained environments (always evolving a single strategy). A: Results for different seedling survival (Blue: Low, $a_{\text {infl }}=0$; Black: High, $a_{\text {infl }}=16$ ). B: Results for different adult mortality (Blue: Low, $S_{\text {adult }}=0.997$; Black: high $S_{\text {adult }}=0.994$ ). 
adult mortality (Fig. 4B, results shown for high adult mortality, in black, and low adult mortality, in blue). As above, this can lead to coexistence of two different strategies: an early germinating, low-variance strategy (low $d_{\mu}$ and low $d_{\sigma}$ ), and a later germinating, highvariance strategy (higher $d_{\mu}$ and high $d_{\sigma}$ ). For both low and high adult mortality, removing any effects of bet-hedging by implementing fine-grained rainfall patterns leads to populations with only a single, fixed strategy of even shorter dormancy periods. Thus, both among- and within-individual variation in germination timing increases due to combinations of lifehistory, bet-hedging and intensity of intraspecific competition.

\section{Discussion}

\section{Modelling results and insights}

Our two complementary modelling approaches have shown how stochastic seasonal environments can select for within- and among-individual variation in germination behavior through interactions between bet-hedging, priority effects due to age-dependent seedling recruitment, and negative frequency-dependent selection. First, our numerical model considering discrete variation ("small" early-germinating vs. "large" late-germinating seeds) reveals ample scope for bet-hedging in a density-independent setting, where long-term geometric growth rates are often highest for populations producing a mixture of the two seed types, whereas arithmetic growth rate is always maximized by producing a single seed type. This model revealed that the two key parameters selecting for seed size variation were those that affect the relative strength of fitness differences among years for the two seed types: the strength of priority effects (competitive advantage to early-germinating small seeds) and the riskiness of early germination (seedling mortality, probability of 'false rains').

Inspired by these results, we next built an evolutionary simulation model of dormancy period, where we included density-dependence as well as continuous within- and among-individual variation in seed size. To do so, we allowed the genotype's mean and variation in dormancy period to evolve independently. We identified the evolution of two distinct germination strategies. One strategy involved the production of seeds with short dormancy periods and low variance in dormancy duration, and the other involved the production of seeds with longer dormancy periods with higher variance in dormancy duration. This second strategy produces high-risk high-reward early germinating seedlings that are competitively superior in years when dry-season rains are sufficient to ensure seedling survival until the start of the wet season. In addition, this strategy also produces late-germinating seedlings that survive (but may suffer a competitive disadvantage) if false rains killed their earlier-germinating siblings. Through comparisons with evolutionary outcomes in fine-grained environments, which did not exhibit this variable strategy, we conclude that this represents a diversifying bet-hedging strategy, where the fitness returns of offspring are decoupled, thus ensuring low genotypelevel variance in fitness (Starrfelt and Kokko 2012). Interestingly, negative frequencydependent selection often led to stable coexistence of these two strategies within populations (Fig. S2), even in simulations initialized without standing genetic variation (via an evolutionary branching event, see Fig. S3). 
bioRxiv preprint doi: https://doi.org/10.1101/2022.01.13.476161; this version posted January 14, 2022. The copyright holder for this preprint (which was not certified by peer review) is the author/funder, who has granted bioRxiv a license to display the preprint in perpetuity. It is made available under aCC-BY-NC 4.0 International license.

The stable coexistence of such distinct germination strategies due to negative frequencydependence has rarely been discussed in the bet-hedging literature (but see Gourbière and Menu 2009). While it is well-known empirically and theoretically that different mechanisms for coping with uncertainty cancel each other out, in the sense that the existence of one riskreducing mechanism reduces the need for another (Venable and Brown 1988; Gerber and Kokko 2018; Haaland et al. 2020) (but see Snyder 2006), little is known about when each of them would be more favored. In specific modeling scenarios one strategy will typically have the advantage over the other, and many studies have looked at optimal or evolutionarily stable combinations of conservative and diversifying bet-hedging (Olofsson et al. 2009; Franch-Gras et al. 2017), or the factors shifting the balance among the two (Einum and Fleming 2004; Crowley et al. 2016). As opposed to simple comparisons of the long-term fitness of the different strategies, the flexible setup of our density-dependent simulation model allowed us to identify negative frequency-dependent selection maintaining both strategies within a population.

Our work demonstrates that explicit consideration of density-dependence in necessary for understanding the adaptive value of both within- and among-individual variation in offspring phenotype in long-lived organisms. Variation in offspring size both within and among individuals is not only common in perennial plants, but also in many other iteroparous organisms including arthropods (Fox and Czesak 2000), birds (Amundsen and Slagsvold 1998), fish (Einum and Fleming 2004), and marine invertebrates (Marshall and Keough 2007). While among-population variation is often interpreted as adaptive, within-individual variation, on the other hand, is mostly viewed as maladaptive (Fox and Czesak 2000). This interpretation is possibly driven by the focus on optimality models (e.g. Smith and Fretwell 1974; Einum and Fleming 2004), which by definition predict a single offspring size to maximize fitness (Metz et al. 2008). Approaches that take frequency-dependent interactions into account, however, show that within-individual variation in offspring size can be adaptive, even in the absence of environmental unpredictability (e.g. Geritz 1995). Our work shows that such an ecological approach is also necessary to understand evolution in unpredictable environments.

\section{Germination strategies in seasonal environments}

Our models were inspired by the wet-dry seasonal dynamics characterizing large parts of the tropics (Feng et al. 2013). Yearly patterns of seedling emergence such as those described by Garwood (1983) for Barro Colorado Island in Panamá suggest that germination during the early part of the rainy season predominates, although there is considerable variation (see also Escobar et al. 2018). Garwood's study also hinted at an important role of priority effects in that seedling emergence in highly competitive light gaps tended to occur earlier than did emergence in less competitive understory habitats. Our models provide a mechanistic explanation for these patterns, and also suggest that ongoing changes in the predictability and temporal variation in precipitation patterns in the tropics may select for altered germination strategies in tropical plants (Feng et al. 2013).

The adaptive challenges faced by plants of seasonal tropical forests are in some ways analogous to those of arctic-alpine plants facing the problem of 'false springs' followed by freezing events, which is thought to select for dormancy or other mechanisms to avoid 
bioRxiv preprint doi: https://doi.org/10.1101/2022.01.13.476161; this version posted January 14, 2022. The copyright holder for this preprint (which was not certified by peer review) is the author/funder, who has granted bioRxiv a license to display the preprint in perpetuity. It is made available under aCC-BY-NC 4.0 International license.

detrimental fitness effects of premature germination (Schwienbacher et al. 2011; Mondoni et al. 2012). Arguing that within-individual variation in germination timing could be beneficial as a bet-hedging trait, Simons \& Johnston (1997) used a model of such a system to illustrate their argument that developmental instability could be adaptive in annuals. During a time when developmental instability was largely seen as maladaptive (c.f. the debate surrounding fluctuating asymmetry), substantial work on bet-hedging strategies has largely resolved this controversy (Zhang and Hill 2005; Devaux and Lande 2010; Scheiner 2014; Tufto 2015), and the dynamics considered by Simons \& Johnson (1997) are now a canonical example of bethedging in seasonal phenology.

A second source of inspiration for our model was the extensive variation in seed size often observed in angiosperms (Michaels et al. 1988), and the many studies reporting relationships between seed size and germination behavior (e.g. Simons and Johnston 2000; Norden et al. 2009; Martins et al. 2019). Although seed size is sometimes thought about as a highly canalized trait (because there should be an optimal balance between size and number of offspring; Smith and Fretwell 1974), both categorical (seed heteromorphism) and continuous variation in seed size is common (e.g. Susko and Lovett-Doust 2000). In a recent phylogenetic analysis, Scholl et al. (2020) analyzed the occurrence of seed heteromorphism in a large sample of the flora of southwestern North America, and detected weak associations between seed heteromorphism and several measures of environmental predictability (aridity and precipitation seasonality). While the tendency for seed heteromorphism to be more likely in more unpredictable environments is consistent with our phenomenological model, these authors explicitly excluded species with continuous variation in seed size from their analyses. Our model predicts that not only seed heteromorphism, but also continuous variation in seed size could represent a bet-hedging strategy in unpredictable environments (c.f. Simons \& Johnston's (1997) suggestion of developmental instability causing adaptive variation in germination timing). Interestingly, Scholl et al. (2020) failed to detect a correlation between seed heteromorphism and the annual life cycle, contrary to their expectations from previous bet-hedging theory. Although seed heteromorphism was more common in annuals than in perennials, they attributed the lack of a detectable effect to the small overall proportion of seed-heteromorphic species. However, the common occurrence of seed heteromorphism also among perennials can further be seen as an indication that the processes interacting with bethedging in our model to produce variation in germination phenology may indeed be common and important in natural systems.

\section{Empirical guidelines and predictions}

Our models yield several testable predictions about the relationship between germination behavior, seed size, and environmental predictability. The simplest prediction arising from our results is that germination behavior and associated traits (e.g. seed size) can vary adaptively within populations, and possibly more so in more unpredictable environments. However, we also find that the distinctions between fine- vs. coarse-grained environmental variation, and among- vs. within-year variation, are important in driving germination patterns. This implies that caution is needed when interpreting measurements of environmental variation and using them to predict ecological gradients of germination strategies. For example, the measurement of rainfall variation used in Scholl et al. (2020) was based on among-year variation (coefficient of variation of annual rainfall measurements) and the 
bioRxiv preprint doi: https://doi.org/10.1101/2022.01.13.476161; this version posted January 14, 2022. The copyright holder for this preprint (which was not certified by peer review) is the author/funder, who has granted bioRxiv a license to display the preprint in perpetuity. It is made available under aCC-BY-NC 4.0 International license.

smallest spatial grid used was $25 \mathrm{~km}^{2}$, both of which might explain the lack of a relationship between rainfall variation and the occurrence of seed heteromorphism. Another reason highlighted by our individual-based model could be that a variable germination strategy (diversifying bet-hedging) is not the only possible adaptation to unpredictable environments, but that alternative, less variable strategies may also occur, and sometimes coexist within populations.

Recent studies of continuous seed size variation and germination behavior in the tropical vine Dalechampia scandens have revealed predictable covariation between measures of environmental predictability and germination behavior. Martins et al. (2019) found that seeds from populations occupying more seasonal environments required longer periods of afterripening (duration of storage required before germination occurs in response to favorable wet conditions) before germinating, and that within each population, smaller seeds required shorter periods of after-ripening. In a follow-up study, Pélabon et al. (2021) considered variation in seed size within individuals and detected a positive relationship between environmental stochasticity and variation in seed size. Environmental unpredictability as defined by Pélabon et al. more closely resembles our parameter $\sigma_{\text {within }}$ in describing stochastic variation in rainfall patterns, and our model thus provides mechanistic support for the hypothesis that the patterns of seed size variation and germination behavior in Dalechampia represents a bet-hedging strategy in unpredictable environments.

While observational studies of germination timing and seed size across ecological gradients may continue to yield insights into variation in these traits, experimental studies would be highly valuable. Seed-sowing experiments with seed families of known descent would specifically allow separating environmental and genetic causes of variation, and lead to insights into the evolutionary potential of germination behavior (e.g. Simons \& Johnson 2006). However, separating the presence of two distinct strategies from continuous variation may continue to prove difficult, especially when the difference in mean behavior between strategies is small, and variation around these means is large.

\section{Limitations and caveats of the model}

Our model results are consistent with empirical patterns of seed size and germination behavior, yet some caution is needed when interpreting the evolution of distinct, coexisting strategies that occurred in our individual-based model. In particular, the specific genetic architecture and simple asexual mode of inheritance we assumed might affect the ability to evolve separate strategies. These issues are not unique to our study, because any evolutionary simulation model of the kind presented here must necessarily make some assumption about the genetic architecture of the traits they model. A major assumption we made is that mean and variance of dormancy duration evolve independently, allowing us to predict the optimal combination of these traits in the absence of any constraints. Evolution of these optimal combinations may be difficult to attain due to genetic constrains, covariation with other traits, or trade-offs.

Importantly, we did not incorporate a trade-off between offspring quality and dormancy period, which could be expected if we assume that seed size is the mechanism by which variation in germination strategy is achieved (Stearns 1989). Furthermore, we did not include a cost to variation (or canalization, see Zhang and Hill 2005). However, while such additional 
bioRxiv preprint doi: https://doi.org/10.1101/2022.01.13.476161; this version posted January 14, 2022. The copyright holder for this preprint (which was not certified by peer review) is the author/funder, who has granted bioRxiv a license to display the preprint in perpetuity. It is made available under aCC-BY-NC 4.0 International license.

assumptions might affect our results (for example by narrowing the parameter space in which variable strategies are selected for if adding a cost to variation, and widening it if adding a cost to canalization), they also reduce generality and do not subtract from the general point. Variation in germination strategies may arise from other sources than simply seed size variation resulting from per-offspring parental investment (Simons and Johnston 2006; Baskin and Baskin 2014) and as with costs of variation vs. canalization, we note that the pattern may also go either way with regards to the seed size vs. germination strategy (offspring quantity vs quality) trade-off: In many species, larger seeds germinate earlier (Biere 1991; Simons and Johnston 2000; Pélabon et al. 2005), but the opposite pattern is also observed (Susko and Lovett-Doust 2000), and among species time to germination is usually longer for larger seeds (Norden et al. 2009; Harel et al. 2011). Thus, while adding some trade-off between seed set and germination strategy might increase realism with respect to certain systems, generality would again necessarily be lowered relative to our present model without such energetic constraints.

Our assumption of a simple asexual reproductive system is also not representative of the majority of plant species. Indeed, plant mating systems are highly variable, and near-complete selfing is uncommon compared to mixed and predominantly outcrossing systems (Moeller et al. 2017). Although we find evolution of two coexisting strategies when using asexual reproduction, gene flow due to random outcrossing might inhibit the emergence of two genetically distinct germination strategies. Therefore, reproductive isolation mechanisms that restrict gene flow between newly arising strategies need to evolve to restore our results in case of sexual reproduction.

In addition to dormancy, germination timing is also driven by variation in flowering and fruiting phenology as well as the duration of fruit maturation (Escobar et al. 2018). Although we chose to keep these processes fixed in our model in order to assess specifically the joint evolution of mean and variation in a single trait (seed size) affecting germination behavior, variation in flowering time additionally leads to non-random mating and is therefore an interesting trait to add in further studies.

\section{Conclusions}

This study has demonstrated novel mechanisms by which variation in germination strategies in perennial plants can evolve, shedding light on the prevalence of seed heteromorphism and continuous seed-size variation seen in perennials as well as annuals. Seed size was historically considered a highly canalized trait, to the point that the weight measurement 'carat' was based on the remarkably invariant seeds of the carob tree (Ceratonia siliqua). However, it has since been discovered that substantial variation in seed size is widespread, even in carob seeds (Turnbull et al. 2006), and its universality begs an explanation. Bet-hedging in desert annuals has previously been the best-studied empirical and theoretical example of variable germination strategies, but there are arguably more perennial species occupying seasonal tropical or temperate environments than there are desert annuals. Our modelling results, where bet-hedging in perennials interacts with unpredictable seasonal variation and competitive priority effects to produce within-individual variation in germination strategies, therefore provide a much-needed extension to existing theory on this topic. A better understanding of competitive dynamics in stochastic seasonal environments can help improve 
the predictability of species and community responses to ongoing changes in climate patterns and other anthropogenic challenges.

\section{Acknowledgments}

The authors thank Hanna Kokko for helpful discussions. HtB and TRH were supported by the Swiss National Science Foundation, on grant number 310030B_182836 awarded to Hanna Kokko. TRH was also supported by the Forschungskredit of the University of Zurich, grant no. FK-21-122.

\section{Author contributions:}

All authors initiated the study. HtB and TRH developed and analyzed the models. HtB ran the simulations. ØHO reviewed the empirical literature. TRH reviewed the theoretical literature and drafted the manuscript with input from all authors.

\section{Data Accessibility Statement:}

All code, code output, and scripts will be made available online upon journal acceptance at Dryad, and is until then available upon request.

\section{References}

Amundsen, T., and T. Slagsvold. 1998. Hatching asynchrony in Great Tits: A bet-hedging strategy? Ecology 79:295-304.

Bårdsen, B.-J., P. Fauchald, T. Tveraa, K. Langeland, N. G. Yoccoz, and R. A. Ims. 2008. Experimental evidence of a risk-sensitive reproductive allocation in a long-lived mammal. Ecology 89:829837.

Baskin, C. C., and J. M. Baskin. 2014. Seeds. Ecology, Biogeography, and Evolution of Dormancy and Germination. 2nd ed. Academic Press, San Diego, US.

Bednekoff, P. A. 1996. Risk-sensitive foraging, fitness, and life histories: Where does reproduction fit into the big picture? Integr. Comp. Biol. 36:471-483.

Biere, A. 1991. Parental effects in Lychnis flos-cuculi. I: Seed size, germination and seedling performance in a controlled environment. J. Evol. Biol. 4:447-465.

Brändel, M. 2004. Dormancy and germination of heteromorphic achenes of Bidens frondosa. Flora 199:228-233.

Chesson, P. 2000. Mechanisms of maintenance of species diversity. Annu. Rev. Ecol. Syst. 31:343366.

Cohen, D. 1966. Optimizing reproduction in a randomly varying environment. J. Theor. Biol. 12:119129.

Crowley, P. H., S. M. Ehlman, E. Korn, and A. Sih. 2016. Dealing with stochastic environmental variation in space and time: bet hedging by generalist, specialist, and diversified strategies. Theor. Ecol. 9:149-161.

Devaux, C., and R. Lande. 2010. Selection on variance in flowering time within and among individuals. Evolution 64:1311-1320.

Donohue, K., R. Rubio De Casas, L. Burghardt, K. Kovach, and C. G. Willis. 2010. Germination, 
bioRxiv preprint doi: $h t t p s: / / d o i . o r g / 10.1101 / 2022.01 .13 .476161$; this version posted January 14 2022. The copyright holder for this preprint (which was not certified by peer review) is the author/funder, who has granted bioRxiv a license to display the preprint in perpetuity. It is made available under aCC-BY-NC 4.0 International license.

postgermination adaptation, and species ecological ranges. Annu. Rev. Ecol. Evol. Syst. 41:293319.

Einum, S., and I. A. Fleming. 2004. Environmental unpredictability and offspring size: Conservative versus diversified bet-hedging. Evol. Ecol. Res. 6:443-455.

Ellner, S. 1985. ESS germination strategies in randomly varying environments. I. Logistic-type models. Theor. Popul. Biol. 28:50-79.

Escobar, D. F. E., R. Rubio de Casas, and L. P. C. Morellato. 2021. Many roads to success: different combinations of life-history traits provide accurate germination timing in seasonally dry environments. Oikos 1-15.

Escobar, D. F. E., F. A. O. Silveira, and L. P. C. Morellato. 2018. Timing of seed dispersal and seed dormancy in Brazilian savanna: Two solutions to face seasonality. Ann. Bot. 121:1197-1209.

Feng, X., A. Porporato, and I. Rodriguez-Iturbe. 2013. Changes in rainfall seasonality in the tropics. Nat. Clim. Chang. 3:811-815. Nature Publishing Group.

Finch-Savage, W. E., and G. Leubner-Metzger. 2006. Seed dormancy and the control of germination. New Phytol. 171:501-523.

Fox, C. W., and M. E. Czesak. 2000. Evolutionary ecology of progeny size in arthropods. Annu. Rev. Entomol. 45:341-369.

Franch-Gras, L., E. M. García-Roger, M. Serra, and M. J. Carmona. 2017. Adaptation in response to environmental unpredictability. Proc. R. Soc. B Biol. Sci. 284.

Fumanal, B., B. Chauvel, A. Sabatier, and F. Bretagnolle. 2007. Variability and cryptic heteromorphism of Ambrosia artemisiifolia seeds: What consequences for its invasion in France? Ann. Bot. 100:305-313.

Furness, A. I., K. Lee, and D. N. Reznick. 2015. Adaptation in a variable environment: Phenotypic plasticity and bet-hedging during egg diapause and hatching in an annual killifish. Evolution 69:1461-1475.

Galloway, L. F. 2001. The effect of maternal and paternal environments on seed characters in the herbaceous plant Campanula americana (Campanulaceae). Am. J. Bot. 88:832-840.

García-Roger, E. M., M. J. Carmona, and M. Serra. 2016. Modes, mechanisms and evidence of bet hedging in rotifer diapause traits. Hydrobiologia, doi: 10.1007/s10750-016-2869-5.

Garwood, N. C. 1983. Seed Germination in a Seasonal Tropical Forest in Panama. Ecol. Monogr. 53:159-181.

Gerber, N., and H. Kokko. 2018. Abandoning the ship using sex, dispersal or dormancy: multiple escape routes from challenging conditions. Philos. Trans. R. Soc. Lond. B. Biol. Sci. 373.

Geritz, S. A. H. 1995. Evolutionarily stable seed polymorphism and small-scale spatial variation in seedling density. Am. Nat. 146:685-707.

Geritz, S., M. Gyllenberg, and J. Toivonen. 2018. Adaptive correlations between seed size and germination time. J. Math. Biol. 77:1943-1968. Springer Berlin Heidelberg.

Gourbière, S., and F. Menu. 2009. Adaptive dynamics of dormancy duration variability: Evolutionary trade-off and priority effect lead to suboptimal adaptation. Evolution 63:1879-1892.

Gremer, J. R., and D. L. Venable. 2014. Bet hedging in desert winter annual plants: Optimal germination strategies in a variable environment. Ecol. Lett. 17:380-387. 
bioRxiv preprint doi: https://doi.org/10.1101/2022.01.13.476161; this version posted January 14 2022. The copyright holder for this preprint (which was not certified by peer review) is the author/funder, who has granted bioRxiv a license to display the preprint in perpetuity. It is made available under aCC-BY-NC 4.0 International license.

Haaland, T. R., J. Wright, and I. I. Ratikainen. 2019. Bet-hedging across generations can affect the evolution of variance-sensitive strategies within generations. Proc. R. Soc. B Biol. Sci. 286. Royal Society Publishing.

Haaland, T. R., J. Wright, and I. I. Ratikainen. 2020. Generalists versus specialists in fluctuating environments: a bet-hedging perspective. Oikos 1-12.

Harel, D., C. Holzapfel, and M. Sternberg. 2011. Seed mass and dormancy of annual plant populations and communities decreases with aridity and rainfall predictability. Basic Appl. Ecol. 12:674-684. Elsevier $\mathrm{GmbH}$.

Hughes, P. W. 2018. Minimal-risk seed heteromorphism: Proportions of seed morphs for optimal risk-averse heteromorphic strategies. Front. Plant Sci. 9:1-9.

Imbert, E. 2002. Ecological consequences and ontogeny of seed heteromorphism. Perspect. Plant Ecol. Evol. Syst. 5:13-36.

Kortessis, N., and P. Chesson. 2019. Germination variation facilitates the evolution of seed dormancy when coupled with seedling competition. Theor. Popul. Biol. 130:60-73. Elsevier Inc.

Levins, R. 1962. Theory of fitness in a heterogeneous environment. I. The fitness set and adaptive function. Am. Nat. 96:361-373.

Marshall, D. J., and M. J. Keough. 2007. The evolutionary ecology of offspring size in marine invertebrates. Adv. Mar. Biol. 53:1-60.

Martins, A. A., Ø. H. Opedal, W. S. Armbruster, and C. Pélabon. 2019. Rainfall seasonality predicts the germination behavior of a tropical dry-forest vine. Ecol. Evol. ece3.5108.

Metcalf, C. J. E., L. T. Burghardt, and D. N. Koons. 2015. Avoiding the crowds: The evolution of plastic responses to seasonal cues in a density-dependent world. J. Ecol. 103:819-828.

Metz, J. A. J., S. D. Mylius, and O. Diekmann. 2008. When does evolution optimize? Evol. Ecol. Res. 10:629-654.

Meyer, S. E., S. G. Kitchen, and S. L. Carlson. 1995. Seed germination timing patterns in intermountain Penstemon (Scrophulariaceae). Am. J. Bot. 82:377-389.

Moeller, D. A., R. D. Briscoe Runquist, A. M. Moe, M. A. Geber, C. Goodwillie, P. O. Cheptou, C. G. Eckert, E. Elle, M. O. Johnston, S. Kalisz, R. H. Ree, R. D. Sargent, M. Vallejo-Marin, and A. A. Winn. 2017. Global biogeography of mating system variation in seed plants. Ecol. Lett. 20:375384.

Mondoni, A., G. Rossi, S. Orsenigo, and R. J. Probert. 2012. Climate warming could shift the timing of seed germination in alpine plants. Ann. Bot. 110:155-164.

Norden, N., M. I. Daws, C. Antoine, M. A. Gonzalez, N. C. Garwood, and J. Chave. 2009. The relationship between seed mass and mean time to germination for 1037 tree species across five tropical forests. Funct. Ecol. 23:203-210.

Olofsson, H., J. Ripa, and N. Jonzén. 2009. Bet-hedging as an evolutionary game: the trade-off between egg size and number. Proc. R. Soc. B Biol. Sci. 276:2963-2969.

Pélabon, C., M. L. Carlson, T. E. Hansen, and W. S. Armbruster. 2005. Effects of crossing distance on offspring fitness and developmental stability in Dalechampia scandens (Euphorbiaceae). Am. J. Bot. 92:842-851.

Pélabon, C., F. De Giorgi, Ø. H. Opedal, G. H. Bolstad, A. Raunsgard, and W. S. Armbruster. 2021. Is there more to within-plant variation in seed size than developmental noise? Evol. Biol., doi: 
bioRxiv preprint doi: $h t t p s: / / d o i . o r g / 10.1101 / 2022.01 .13 .476161$; this version posted January 14 2022. The copyright holder for this preprint (which was not certified by peer review) is the author/funder, who has granted bioRxiv a license to display the preprint in perpetuity. It is made available under aCC-BY-NC 4.0 International license.

10.1007/s11692-021-09544-y. Springer US.

Pinceel, T., B. Vanschoenwinkel, W. Hawinkel, K. Tuytens, and L. Brendonck. 2017. Aridity promotes bet hedging via delayed hatching: a case study with two temporary pond crustaceans along a latitudinal gradient. Oecologia 184:161-170. Springer Berlin Heidelberg.

Poethke, H. J., T. Hovestadt, and O. Mitesser. 2016. The evolution of optimal emergence times: bet hedging and the quest for an ideal free temporal distribution of individuals. Oikos 125:16471656.

Rees, M. 1996. Evolutionary ecology of seed dormancy and seed size. Philos. Trans. R. Soc. B Biol. Sci. 351:1299-1308.

Rees, M., D. Z. Childs, K. E. Rose, and P. J. Grubb. 2004. Evolution of size-dependent flowering in a variable environment: Partitioning the effects of fluctuating selection. Proc. R. Soc. B Biol. Sci. 271:471-475.

Rubio de Casas, R., C. G. Willis, W. D. Pearse, C. C. Baskin, J. M. Baskin, and J. Cavender-Bares. 2017. Global biogeography of seed dormancy is determined by seasonality and seed size: a case study in the legumes. New Phytol. 214:1527-1536.

Scheiner, S. M. 2014. Bet-hedging as a complex interaction among developmental instability, environmental heterogeneity, dispersal, and life-history strategy. Ecol. Evol. 4:505-515.

Scholl, J. P., L. Calle, N. Miller, and D. L. Venable. 2020. Offspring polymorphism and bet hedging: a large-scale, phylogenetic analysis. Ecol. Lett. 23:1223-1231.

Schwienbacher, E., J. A. Navarro-Cano, G. Neuner, and B. Erschbamer. 2011. Seed dormancy in alpine species. Flora Morphol. Distrib. Funct. Ecol. Plants 206:845-856. Elsevier GmbH.

Seger, J., and H. J. Brockmann. 1987. What is bet-hedging? Oxford Surv. Evol. Biol. 4:182-211.

Simons, A. M. 2011. Modes of response to environmental change and the elusive empirical evidence for bet hedging. Proc. R. Soc. B Biol. Sci. 278:1601-1609.

Simons, A. M. 2014. Playing smart vs. playing safe: The joint expression of phenotypic plasticity and potential bet hedging across and within thermal environments. J. Evol. Biol. 27:1047-1056.

Simons, A. M., and M. O. Johnston. 1997. Developmental instability as a bet-hedging strategy. Oikos 80:401-406.

Simons, A. M., and M. O. Johnston. 2006. Environmental and genetic sources of diversification in the timing of seed germination: Implications for the evolution of bet hedging. Evolution 60:2280.

Simons, A. M., and M. O. Johnston. 2000. Variation in seed traits of Lobelia inflata (Campanulaceae): Sources and fitness consequences. Am. J. Bot. 87:124-132.

Smith, C. C., and S. D. Fretwell. 1974. The optimal balance between size and number of offspring. Am. Nat. 108:499-506.

Snyder, R. E. 2006. Multiple risk reduction mechanisms: Can dormancy substitute for dispersal? Ecol. Lett. 9:1106-1114.

Starrfelt, J., and H. Kokko. 2012. Bet-hedging - a triple trade-off between means, variances and correlations. Biol. Rev. 87:742-755.

Stearns, S. C. 1989. Trade-offs in life-history evolution. Funct. Ecol. 3:259-268.

Susko, D. J., and L. Lovett-Doust. 2000. Patterns of seed mass variation and their effects on seedling 
traits in Alliaria petiolata (Brassicaceae). Am. J. Bot. 87:56-66.

Tange, O. 2021. GNU Parallel. Zenodo.

ten Brink, H., J. R. Gremer, and H. Kokko. 2020. Optimal germination timing in unpredictable environments: the importance of dormancy for both among- and within-season variation. Ecol. Lett., doi: 10.1111/ele.13461.

Torres-Martínez, L., P. Weldy, M. Levy, and N. C. Emery. 2017. Spatiotemporal heterogeneity in precipitation patterns explain population-level germination strategies in an edaphic specialist. Ann. Bot. 119:253-265.

Tremayne, M. A., and A. J. Richards. 2000. Seed weight and seed number affect subsequent fitness in outcrossing and selfing Primula species. New Phytol. 148:127-142.

Tufto, J. 2015. Genetic evolution, plasticity, and bet-hedging as adaptive responses to temporally autocorrelated fluctuating selection: A quantitative genetic model. Evolution 69:2034-2049.

Turnbull, L. A., L. Santamaria, T. Martorell, J. Rallo, and A. Hector. 2006. Seed size variability: From carob to carats. Biol. Lett. 2:397-400.

Varpe, $\varnothing$. 2017. Life history adaptations to seasonality. Integr. Comp. Biol. 57:943-960.

Venable, D. L. 2007. Bet hedging in a guild of desert annuals. Ecology 88:1086-1090.

Venable, D. L. 1985. The evolutionary ecology of seed heteromorphism. Am. Nat. 126:577-595.

Venable, D. L., and J. S. Brown. 1988. The selective interactions of dispersal, dormancy, and seed size as adaptations for reducing risk in variable environments. Am. Nat. 131:360-384.

Venable, D. L., A. Búrquez, G. Corral, and E. Morales. 1987. The ecology of seed heteromorphism in Heterosperma pinnatum in central Mexico. Ecology 68:65-76.

Venable, D. L., and L. Lawlor. 1980. Delayed germination and dispersal in desert annuals: Escape in space and time. Oecologia 46:272-282.

Vleeshouwers, L. M., H. J. Bouwmeester, and C. M. Karssen. 1995. Redefining seed dormancy: An attempt to integrate physiology and ecology. J. Ecol. 83:1031.

Wagmann, K., N. C. Hautekèete, Y. Piquot, C. Meunier, S. E. Schmitt, and H. Van Dijk. 2012. Seed dormancy distribution: Explanatory ecological factors. Ann. Bot. 110:1205-1219.

Wang, C.-C., and D. C. Rogers. 2018. Bet hedging in stochastic habitats: an approach through large branchiopods in a temporary wetland. Oecologia 188:1081-1093. Springer Berlin Heidelberg.

Wang, H. L., L. Wang, C. Y. Tian, and Z. Y. Huang. 2012. Germination dimorphism in Suaeda acuminata: A new combination of dormancy types for heteromorphic seeds. South African J. Bot. 78:270-275. Elsevier B.V.

Yao, S., H. Lan, and F. Zhang. 2010. Variation of seed heteromorphism in Chenopodium album and the effect of salinity stress on the descendants. Ann. Bot. 105:1015-1025.

Zhang, X. S., and W. G. Hill. 2005. Evolution of the environmental component of the phenotypic variance: Stabilizing selection in changing environments and the cost of homogeneity. Evolution 59:1237-1244. 


\section{Supplementary material}

\section{Part 1: Results without priority effects}

In the absence of priority effects, individuals will evolve a mean germination period of about 26.5 weeks, independent of the variation in rainfall (Fig S1A). Within-individual variation in dormancy period $d_{\sigma}$ evolves to values close to 0 (Fig S1B). We find this result in both coarseand fine-grained environments. The evolved genotypes result in dormancy period of 26 or 27 weeks (Fig S1C).

Note that seeds will only germinate if the rainfall $R_{t}$ exceeds the threshold value $R_{\text {thres. }}$ Seeds with a dormancy period of 26 weeks, will therefore not experience a dry week, since they will only germinate in last week of the dry season if it has enough rain to trigger germination.

A

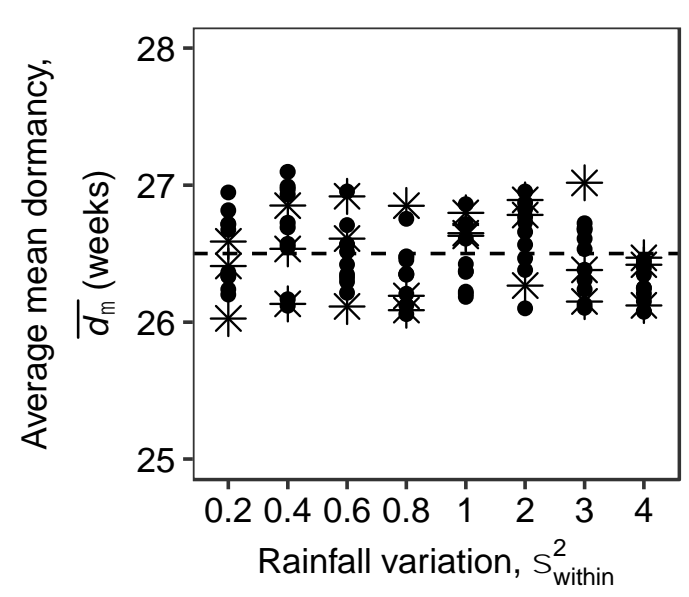

C

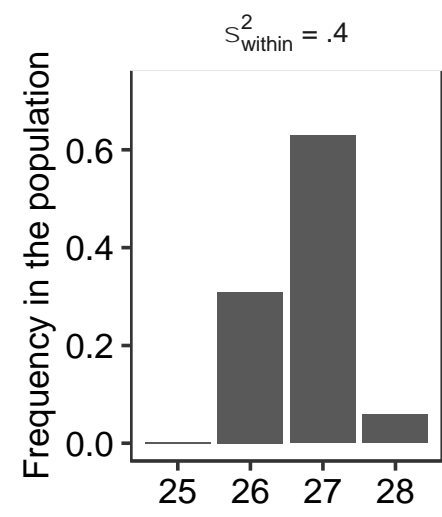

B

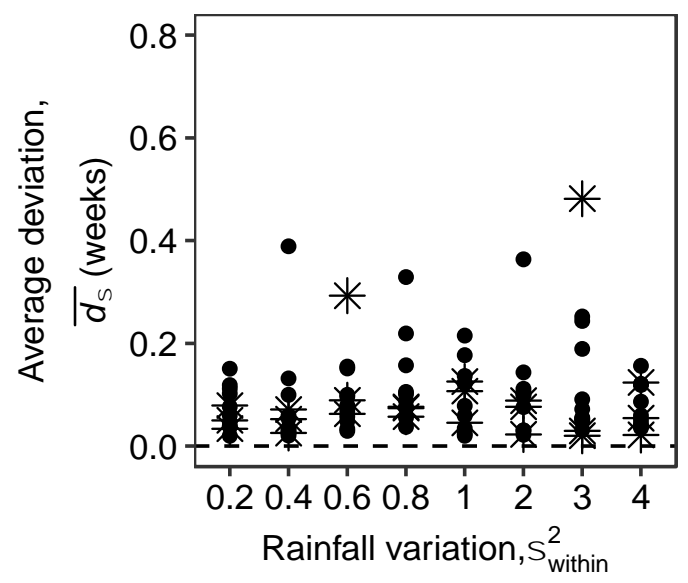

${ }_{\text {within }}^{2}=3$

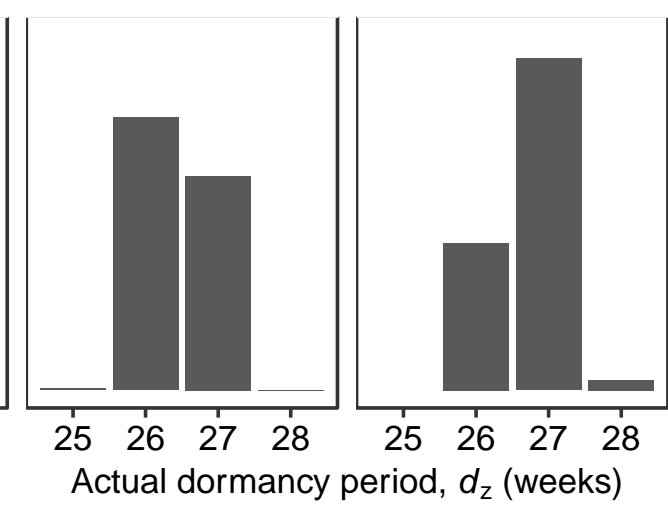
${ }_{\text {within }}^{2}=4$

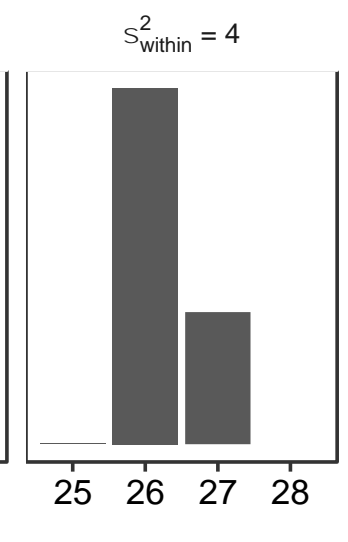

Fig S1: Mean evolved traits (panels A and B) and the resulting phenotypes in the population (panel c) after 100.000 years of evolution in the absence of priority effects over a range of values of within-year rainfall variability $\sigma^{2}$ within. Panels A and B: The dots show coarse-grained and stars fine-grained environments. In panel C, we show the resulting phenotypes for the replicate with the highest value for $\sigma$, under some of the $\sigma_{\text {within }}^{2}$ scenarios. Parameters are as in table 1. 
bioRxiv preprint doi: https://doi.org/10.1101/2022.01.13.476161; this version posted January 14, 2022. The copyright holder for this preprint (which was not certified by peer review) is the author/funder, who has granted bioRxiv a license to display the preprint in perpetuity. It is made available under aCC-BY-NC 4.0 International license.

\section{Part 2: Invasion dynamics and evolutionary branching}

In some parameter regions, we observe alternatively a single strategy or two coexisting strategies in the population at the end of the evolutionary simulations. Here, we show that both strategies (long mean dormancy and high variation in dormancy period; short mean dormancy and no or low variation in dormancy period) have an evolutionary advantage when invading a resident population of the other strategy (Fig. S2). As a representative example, we use the genotypes that evolved in the purple replicate in Fig. 3 in the main text. Because of this negative frequency-dependence, we interpret any observations of only a single strategy being present in the population at the end of the simulation as a result of transient dynamics, e.g. that stochastic events causing the extinction of one strategy, and that the right (multilocus) mutations have not yet occurred to allow it to re-establish.
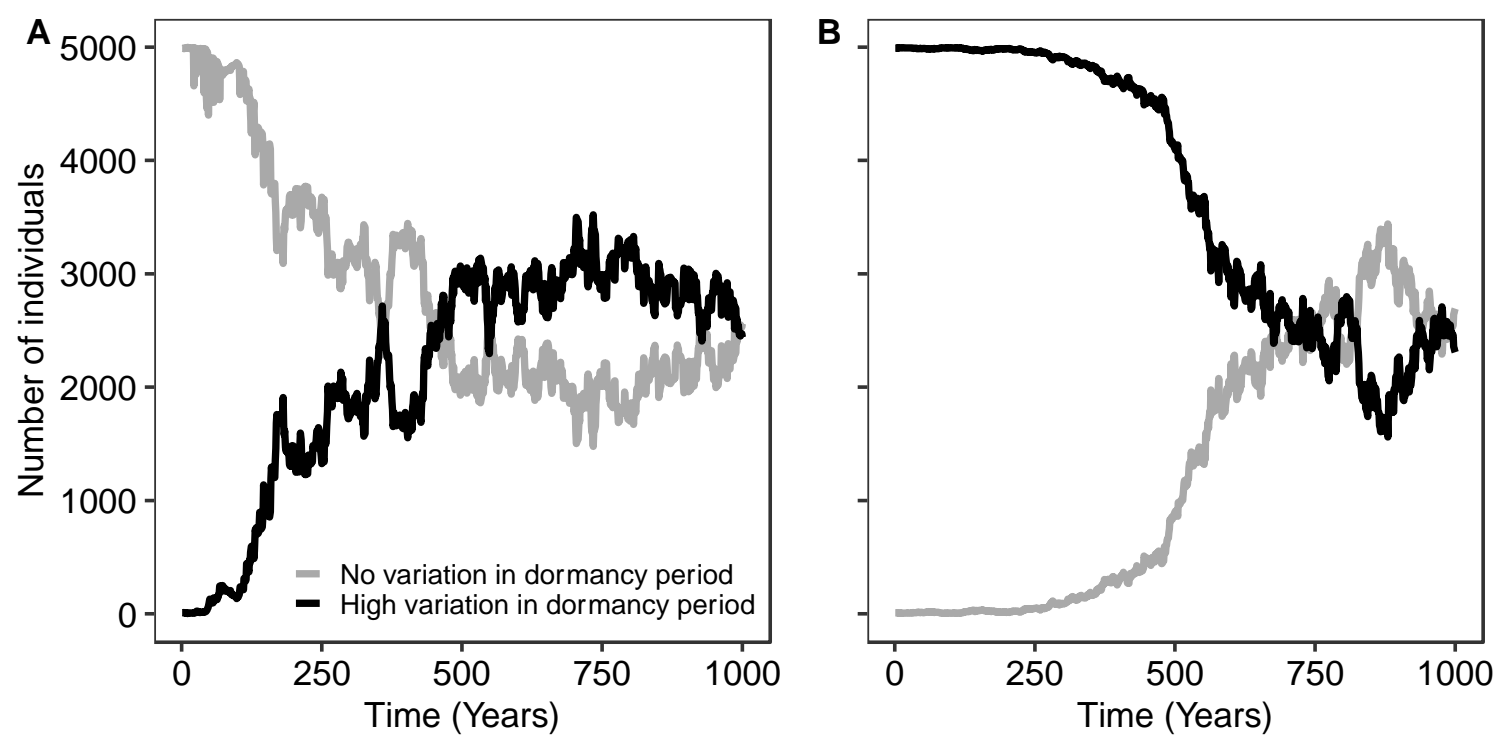

Fig S2: Ecological time series for two situations with a highly unpredictable dry season and two coexisting strategies. The black strategy produces seeds with late mean and high variation in dormancy period $\sim \mathrm{N}\left(22.3,1.07^{2}\right)$; the grey strategy has seeds with short mean and low variation in dormancy period, $\sim \mathrm{N}\left(21.2,0.07^{2}\right)$. These are the strategies at the end of the simulation of the purple population in Fig. 3 . In the dry season the rainfall is normally distributed with $\sim \mathrm{N}(0,2)$, which means that the probability to get a raintriggering event (rain $\geq 1$ ) is $\approx 24 \%$. Panel A shows ecological dynamics when the black strategy (10 individuals) invades a population where the grey strategy is resident (4990 individuals) at carrying capacity, while in panel B the grey strategy invades the black population. Default parameters otherwise (See table 1).

We also ran additional simulations initiating the populations with no genetic variation in $d_{\mu}$ and $d_{\sigma}$, in order to check whether separate strategies evolved also in this case, and not just as a consequence of initiating the populations with sufficient standing genetic variation. The resulting time series (Fig. S3) demonstrate that a single two-locus strategy evolves at first, until an evolutionary branching point is reached whereafter two separate strategies evolve and stably coexist. 

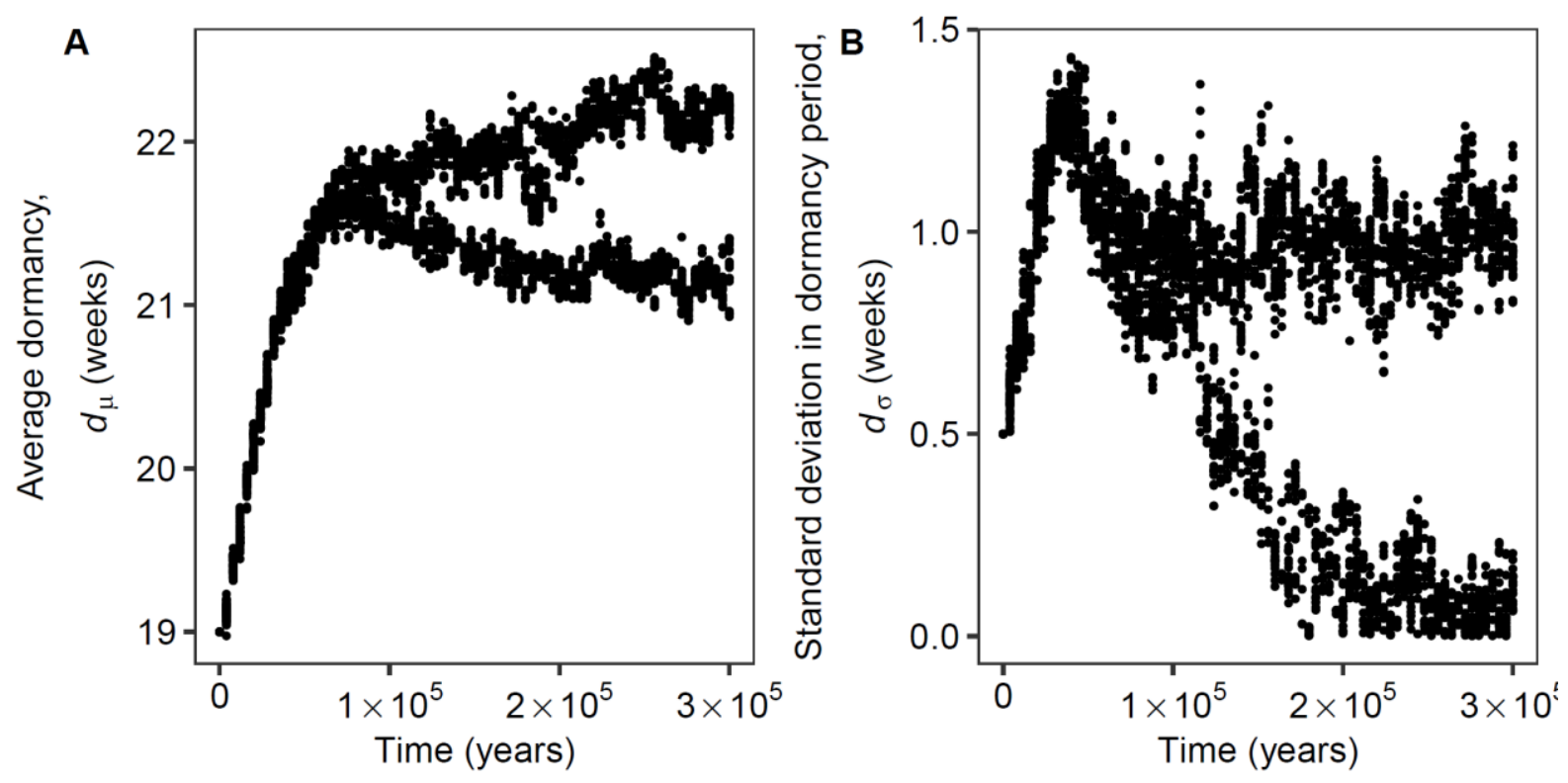

Figure S3: Evolutionary time series of the two evolving traits (mean dormancy period, $d_{\mu}$, in panel A and standard deviation in dormancy period, $d_{\sigma}$, in panel B), when starting the simulations without any genetic variation $\left(d_{\mu}=19\right.$ and $d_{\sigma}=0.5$ for all individuals). Points represent a random subset $(1 \%)$ of the individuals in the population at a given time step. Initially the population evolves a single strategy, but after an evolutionary branching point is reached the populations splits into different strategies. For computational purposes, the mutation rate for both traits was increased to a value of $m=0.1$. In the dry season the rainfall is normally distributed with $\sim \mathrm{N}(0,2)$, default parameters were otherwise used (table 1$)$. 
bioRxiv preprint doi: https://doi.org/10.1101/2022.01.13.476161; this version posted January 14, 2022. The copyright holder for this preprint (which was not certified by peer review) is the author/funder, who has granted bioRxiv a license to display the preprint in perpetuity. It is made available under aCC-BY-NC 4.0 International license.

\section{Part 3: Less or more variation in rainfall}

Here we present simulation results with lower (Fig. S4) or higher (Fig. S5) variation in dry season rainfall, $\sigma_{\text {within. }}^{2}$ Comparing these results with those in Fig. $3\left(\sigma^{2}\right.$ within $\left.=2\right)$, we observe that lower rainfall variation (Fig. $\mathrm{S} 4, \sigma^{2}$ within $=0.4$ ) leads to longer average dormancy $d_{\mu}$, as early germination becomes more risky. Furthermore, we observe a decrease in both withinindividual dormancy variation (lower $d_{\sigma}$ ), and among-individual genetic variation (fewer of the simulations end up with two coexisting strategies). In contrast, increasing rainfall variation (Fig. S5, $\sigma_{\text {within }}^{2} 4$ ) leads to both higher $d_{\sigma}$ and increased among-individual variation.
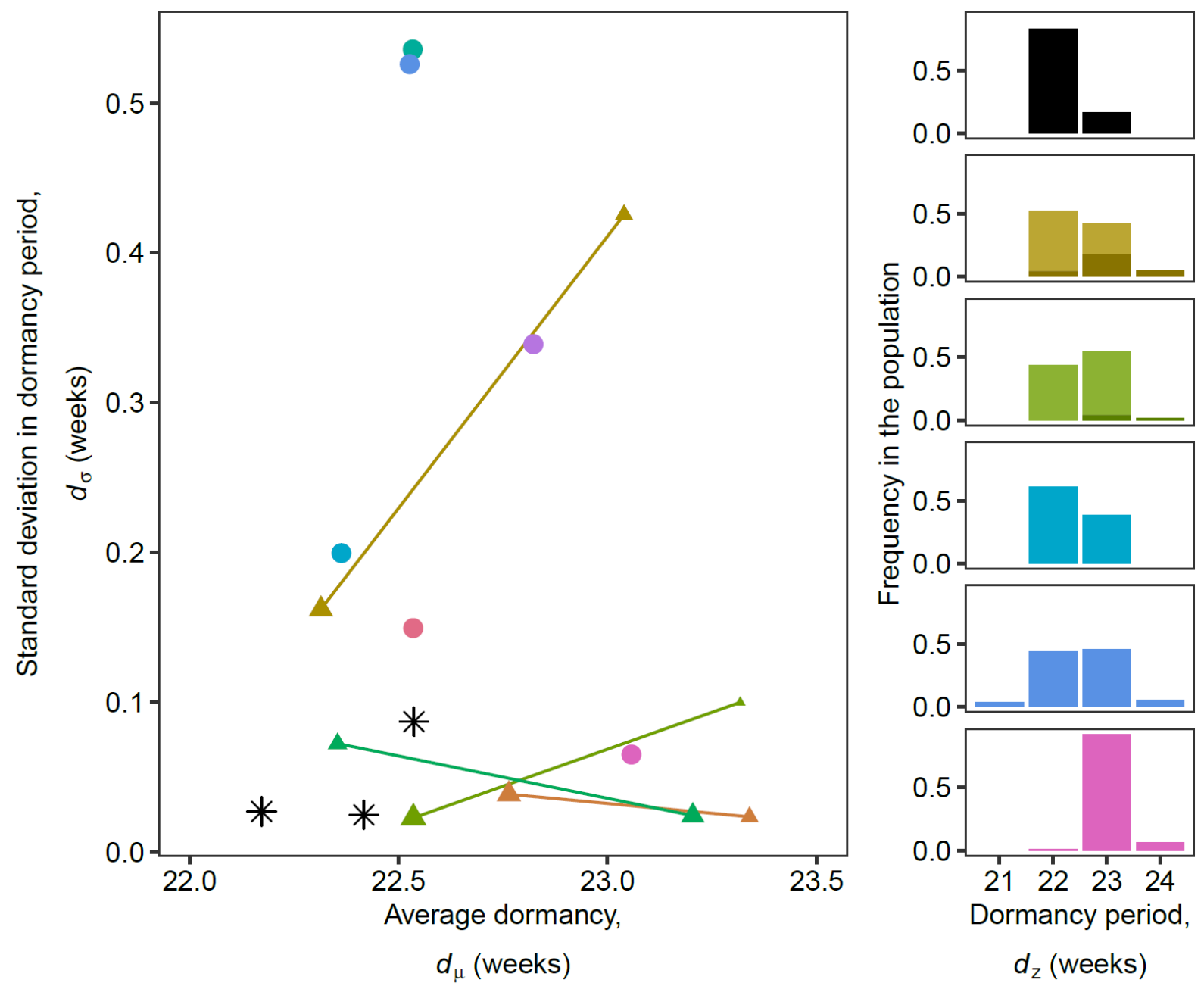

Figure S4: Left panel shows average evolved seed dormancy strategies combining dormancy period $\left(\mathrm{d}_{\mu}\right)$ and standard deviation in dormancy period $\left(\mathrm{d}_{\sigma}\right)$ when dry season rainfall variance $\sigma^{2}{ }_{\text {within }}=0.4$. (See table 1 for other baseline parameter values.) Each population is represented in trait space by one coloured point if exhibiting a single strategy at the end of the simulation (circle), or two points if two strategies coexisted in the population at the end of the simulation (triangles connected by a solid line), with point sizes proportional to the fraction of the population using each strategy. Black stars represent populations in fine-grained environments (always evolving a single strategy). Histograms on the right shows the distributions of the actual dormancy periods dictated by the genotypes in the population. Histogram colors correspond to point color in the left panel; for simulations with two coexisting strategies the distribution of dormancy periods is plotted in a darker hue for the strategy with higher $\mathrm{d}_{\sigma}$. 

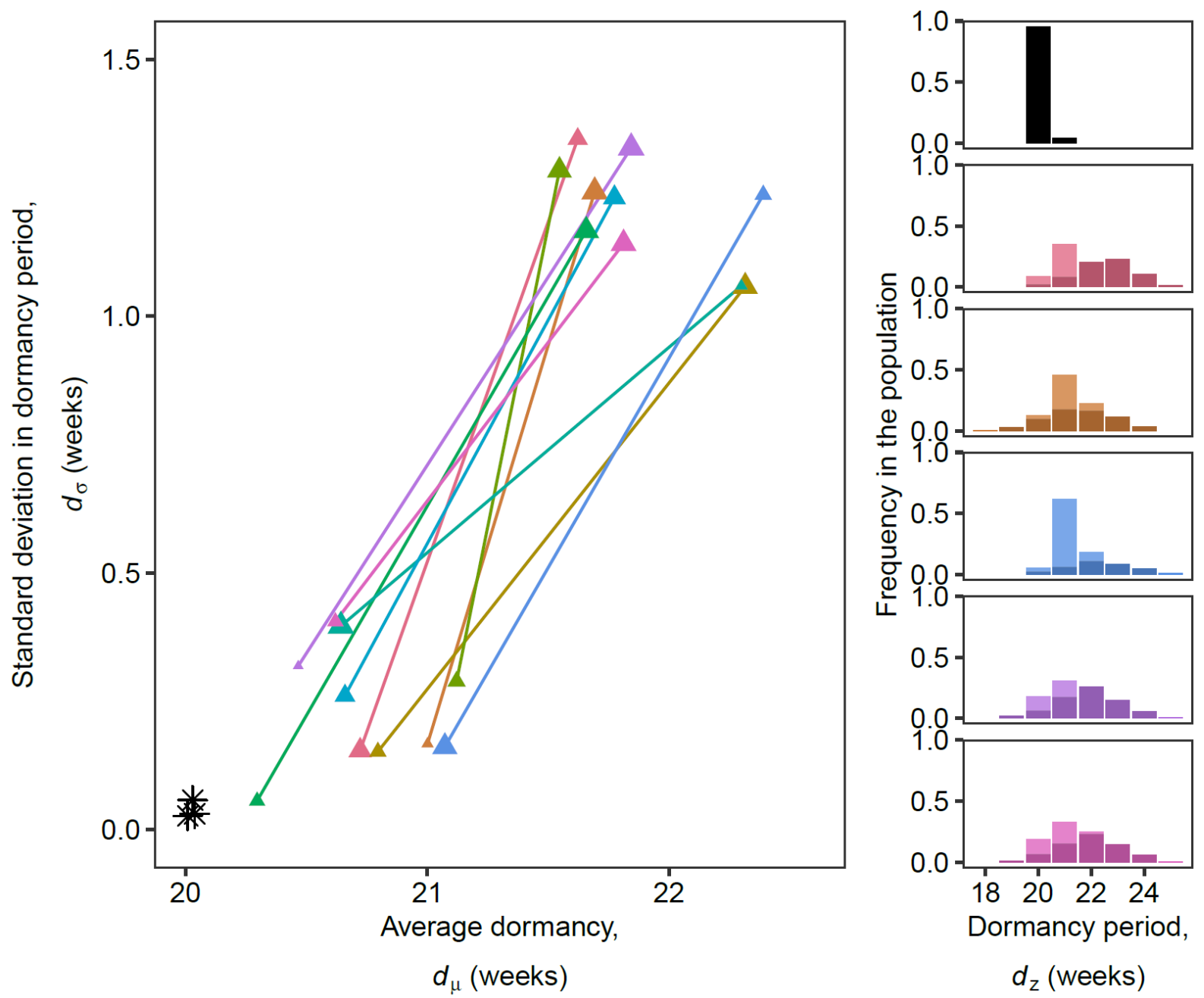

Figure S5: Left panel shows average evolved seed dormancy strategies combining dormancy period $\left(d_{\mu}\right)$ and standard deviation in dormancy period $\left(d_{\sigma}\right)$ when dry season rainfall variance $\sigma^{2}$ within $=4$. (See table 1 for other baseline parameter values.) Each population is represented in trait space by two triangles connected by a solid line if two strategies coexisted in the population at the end of the simulation, with triangle sizes proportional to the fraction of the population using each strategy. Black stars represent populations in fine-grained environments (always evolving a single strategy). Histograms on the right shows the distributions of the actual dormancy periods dictated by the genotypes in the population. Histogram colors correspond to point color in the left panel; for simulations with two coexisting strategies the distribution of dormancy periods is plotted in a darker hue for the strategy with higher $d_{\sigma}$. 